\title{
Changes in future synoptic circulation patterns: consequences for extreme event attribution
}

\author{
Davide Faranda, ${ }^{1,2 *}$ Mathieu Vrac, ${ }^{1}$ Pascal Yiou $^{1}$, Aglaé Jézéquel $^{3,4}$, Soulivanh Thao ${ }^{1}$ \\ ${ }^{1}$ Laboratoire des Sciences du Climat et de l'Environnement \\ CE l'Orme des Merisiers, UMR 8212 CEA-CNRS-UVSQ \\ Université Paris-Saclay \& IPSL, 91191 Gif-sur-Yvette, France \\ ${ }^{2}$ London Mathematical Laboratory, 8 Margravine Gardens, London, W68RH, UK \\ ${ }^{3}$ École des PontsParisTech, Champs sur Marne, France \\ ${ }^{4}$ LMD/IPSL, Ecole Normale Superieure, PSL research University, Paris, France
}

*To whom correspondence should be addressed; E-mail: davide.faranda@1sce.ipsl.fr

September 30, 2019

\begin{abstract}
Anthropogenic emissions can modify the frequency and intensity of extreme weather events such as cold-spells, heat-waves and heavy precipitations. A major challenge is to detect changes in the atmospheric circulation patterns associated to those extreme events. The emergence of patterns depends on the chaotic behavior of the atmospheric flow and can also be modified by anthropogenic emissions. By embedding the circulation patterns observed during selected extremes into historical climate simulations and projections based on emission scenarios, we find major changes in probability, predictability and persistence of atmospheric patterns observed during extreme events using an analog based method. The results highlight the need to take into account the role of atmospheric circulation in attribution studies as future
\end{abstract}




\section{${ }_{17}$ Significance}

Weather extreme events greatly impact agricultural, social and economic activities. In a changing climate, it seems primordial to ask how anthropogenic emissions impact the frequency and intensity of extreme events. Attribution studies focus on this issue, often assuming that the atmospheric circulation associated to extreme events is not itself affected by climate changes. Here we show that the synoptic patterns associated to extreme events will be greatly affected by anthropogenic forcing. These results warn that such changes must be taken into account in future research to perform meaningful attribution studies

\section{Introduction}

Understanding to what extent an extreme weather event is caused or modified by anthropogenic climate change is a challenging scientific question. One of the outcomes of extreme event attribution (EEA) is an estimate of how the probability of an event is altered with climate change $(1,2)$. Many local or regional extremes of temperature or precipitation are driven by features of the synoptic circulation $(3,4)$. Focusing on the relations between extremes and the circulation is part of a general "storyline" approach to EEA (5). Assessing changes in the synoptic circulation was deemed as a major scientific challenge (6-8). One of the difficulties has a statistical nature due to the rarity of the multivariate features of the circulation leading to extremes. The other major difficulty is of physical nature, related to the chaotic behavior of the atmosphere (9) and the complexity introduced by other components of the climate system (oceans, vegetation, sea and continental ice, volcanoes). This generates an intrinsic variability on a wide range of spatial and temporal scales which can affect the occurrence and intensity of extreme events. On top of this, the climate system is never on a stationary state: external forcings, both natural 
(solar activity, volcanic eruptions, orbital parameters) and anthropogenic (greenhouse gases emissions, land use cover changes) change continuously on a wide range of temporal scales (10, 11). This non stationarity is difficult to tackle from both statistical and physical perspectives. Here, we develop a new paradigm to treat this challenge of estimating shifts in rare atmospheric patterns.

Previous studies have focused on detecting significant global and average shifts in the atmospheric circulation pattern under anthropogenic forcing $(6,12-16)$. At this point, there is no general consensus on the existence and direction of a potential shift. In contrast, little attention has been devoted to the evolution of circulation patterns related to specific observed weather events (17-19). The originality of this article is to use the framework of dynamical systems theory applied to these specific observed circulation patterns. We aim to understand how likely, persistent and predictable those patterns will be under different greenhouse gases emissions scenarios. We build our studies on the analogs theory and the results presented in $(20,21)$. The main idea is to follow the atmospheric flow in its full phase space, avoiding to project it onto specific and empirical indices (such as North Atlantic Oscilation (NAO), Arctic Oscillation (AO)) and compute the recurrences (analogs) properties of the circulation patterns associated to extreme events. Indeed, (21) have shown that robust changes of atmospheric circulation patterns under anthropogenic emissions can be identified with this methodology.

We test our methodology on recent observed examples of different classes of extreme events in Europe (cold spells, heatwaves and extreme precipitations) and their associated circulation patterns and we detect their changes using global coupled climate models from the CMIP5 (Coupled models inter-comparison project) ensemble. 
We select 12 different extreme events: 4 cold spells, 4 heatwaves and 4 extreme precipitations (see Table 1 for event descriptions). The selection of these events is based on their socioeconomic impacts and is detailed in the Supplementary Material. All these events affected one or more European countries and they are associated to specific circulation patterns. We define the circulation on a region corresponding to the North Atlantic basin and Europe [22.5N-70N, $80 \mathrm{~W}-50 \mathrm{E}]$. This region has been already used in studies based on analogs (18), and on weather patterns (22-24). We use geopotential height at 500mb (hereafter Z500), issued from the NCEP reanalysis as proxy for atmospheric circulation.

We extract the daily Z500 fields corresponding to the selected extreme event (average Z500 maps anomalies during the events are shown in Figure 1). We then embed these observed trajectories into historical simulations (1951-2000), and projections (2051-2100) under a medium (RCP4.5) and high (RCP 8.5) emissions scenarios (25) of the CMIP5 models given in Table S1. Data are regridded to the NCEP spatial resolution. When we embed the portion of Z500 trajectories corresponding to extreme events, we assume that the circulation patterns associated to the extreme event are observed in the climate model simulations. Given that the models have biased representation of the geopotential heights, we apply a statistical bias correction - allowing to account for climate change (26) — on the Z500 fields, before the analysis. Since there is a trend on Z500 fields directly related to the surface temperature, we present the results for a bias correction on the raw Z500 field as well as for a bias correction on detrended Z500 fields. Details about the bias correction and detrending procedures are given in the Supplementary Material.

For each extreme event, we compute the analogs of the observed synoptic patterns in each set 
of model simulations, and determine their properties. For each daily Z500 field observed during extreme events, we select the closest $2 \%$ of daily Z500 fields using Euclidean distance. This defines our analogs ensemble. Note that the results do not crucially depend on this percentage provided that it is in the range of 0.5 to $3 \%$. The values of the Euclidean distance allow to determine how well the circulation patterns associated to extreme events fit in the simulations. In addition to this metric (hereafter called analogs quality and precisely defined as the average of the Euclidian distance of the $2 \%$ closest fields), we compute the predictability $d$ and persistence $\theta^{-1}$ metrics (20) (see Supplementary material). Those parameters describe the recurrences of a system around a state in phase space. In our case, the state is the Z500 map for a given extreme event. Values of $d$ and $\theta^{-1}$ are obtained for every day in the dataset of interest. $d$ provides information on the number of pathways the system can take to reach and leave a state, and it acts as a proxy for the systems active number of degrees of freedom around the state of interest. $\theta^{-1}$ describes the persistence of an atmospheric circulation state in time, i.e. how long the system typically stays around the state of interest. A very persistent state (i.e., with a large $\theta^{-1}$ ) is highly stable (and therefore also highly predictable), while a very unstable state yields low persistence.

By repeating this procedure for all models and scenario runs, we can detect changes in the atmospheric circulation observed during extreme events. A change in the analogs quality will tell us whether the atmospheric configuration is more or less likely in the historical than in the scenario experiments. A change in the dynamical indices will inform us on the change of predictability and persistence of the circulation pattern associated to the extreme event. 


\section{Results}

Figure 2 shows the change in the atmospheric circulation associated to climate change in terms of relative changes $\left(x_{\mathrm{RCP}}-x_{\mathrm{HIST}}\right) / x_{\mathrm{HIST}}$ where $x$ is alternatively the analogs quality, the predictability $d$ and the persistence $\theta^{-1}$ for each of the events considered in this study. Individual results for each event are displayed in Figure S1-S12 in the Supplementary material. As an indicator of significance of the results, we use the number of models yielding changes of the same sign for the analogs quality (size of the circles in Figure 2). Panels a) and b) (respectively c) and d)) corresponds to non-detrended (respectively detrended) bias correction for RCP 4.5 Scenario (a) and c) and RCP 8.5 Scenario (b) and (d). Figure 3 shows the same results with a bar representation for RCP 4.5 (a) and RCP 8.5 scenario (b).

We first begin with the results for the non-detrended results shown in Figure 2-a,b and bars with blue edges in Figure 3. We note that different classes of extreme events have similar responses: all heatwaves yield better analogs in RCP4.5 and RCP 8.5 than in the historical periods (i.e., negative change in the average Euclidean distance), although more slightly for RCP8.5. We also remark that the model agreement on the sign of changes is very low for the RCP8.5 scenario, possibly meaning that the circulation deviates too much from the observed patterns to be observed under very large greenhouse gases forcing. All the heatwaves suffer of a decrease in predictability $(5-10 \%)$ and a decrease in the persistence (10-15\%). Cold spells become less likely in the RCP 4.5 ( $\approx 5 \%$ less) and RCP 8.5 (10-15\% less) scenarios. They all become more persistent but interestingly, the predictability depends on the event considered. For the patterns connected to precipitation events, results strongly depend on the event considered. Overall, we find that the changes in the patterns associated to the extreme events are most of the time significant: there is a large agreement among different models on the sign of these changes. The 
intensity of the changes is approximately of $10 \%$ and therefore not negligible.

We analyse the effect of detrending (Figure 2-c,d and bars with red edges in Figure 3). In general, detrending reduces the magnitude of changes for the three indicators because we are looking at residuals. Those residuals between detrended and non-detrended analysis can be interpreted as the part of changes not directly linked to the thermodynamic trend on Z500, since the trend in Z500 are a direct consequence of antrhopogenic emissions. For some events, the changes in the detrended data have an opposite sign, e.g. the analogs quality for heatwave events which decreases in the RCP 8.5 scenario. This implies that the circulation patterns associated to the examined heatwaves are less probable in a RCP 8.5 scenario than in present climate. This does not mean that there will be no heatwaves - as it has been shown by numerous studies that anthropogenic climate change has led and will lead to more heatwaves (27) - but rather that there will be other kinds (or even unprecedented) heatwave events.

\section{Discussion}

We have provided a framework for attributing to climate change synoptic circulations associated to extreme events. Our analysis provides a range of indicators, which inform on the likelihood of observing those circulation patterns in future emission scenarios, and estimate their changes in predictability and persistence. Different extreme events have different responses to climate change. We however found similarities within each class of extremes. Performing a detrended or not detrended bias correction also affects the results and allows to separate the thermodynamic effect in the increase of the geopotential height from the residual anomalies.

This study comes with some caveats. Models have biases in synoptic patterns associated to extreme events as they are marked by blocking, strong gradients of even cut-offs in the 
Z500 fields. They also have different mean global and local temperatures and this affects the average height of Z500 data. This motivated our need for performing a bias correction. Another caveat comes from the stationarity hypothesis on 50 years periods used to pick up the analogs field. Detrending partly answers this problem and allows to compute the residual changes. Another limitation is the use of the Z500 field as a proxy of the synoptic circulation. It does not completely capture the synoptic circulation of the atmosphere. The time and spatial scale of the Z500 field may affect the results. The sensitivity of our analysis in the choice of the domain analyzed is reflected in the different quality of the results for heatwaves/coldspells with respect to flood events. Indeed the synoptic patterns leading to high precipitation yield a smaller scale, as shown in $(19,28))$. The role of convection for these events could also be taken into account (29).

The method presented has the advantage of being a very flexible and fast tool that could be applied in real time to observed (and potentially forecasted) extreme weather events. This would be a way to complete extreme event attribution diagnostics on the role of anthropogenic as well as natural climate change on the synoptic circulation leading to the observed event (30). The evaluation of which extreme events are and will become more or less predictable could be useful to improve weather forecast and climate projections (31). While previous studies mostly focus on single extreme events attribution our method is completely general and can be potentially applied to all possible class of extreme events. Our results also express the need of including the role of atmospheric circulation in attribution studies (32). Further developments of this tool could include the recent extensions of dynamical system techniques to take into account multiple variables (33), that can be used for studying compound events (34). 


\section{References}

1. A. Jézéquel, et al., Climatic Change (2018).

2. A. Toreti, et al., Earth's Future 7, 652 (2019).

3. P. Yiou, M. Nogaj, Geophysical Research Letters 31 (2004).

4. K. E. Trenberth, J. T. Fasullo, T. G. Shepherd, Nature Clim. Change 5, 725 (2015).

5. T. G. Shepherd, Current Climate Change Reports 2, 28 (2016).

6. T. G. Shepherd, Nature Geoscience 7, 703 (2014).

7. C. B. Field, V. Barros, T. F. Stocker, Q. Dahe, Managing the risks of extreme events and disasters to advance climate change adaptation: special report of the intergovernmental panel on climate change (Cambridge University Press, 2012).

8. J. Sillmann, et al., Weather and climate extremes 18, 65 (2017).

9. E. N. Lorenz, Journal of the atmospheric sciences 20, 130 (1963).

10. V. Lucarini, K. Fraedrich, F. Lunkeit, arXiv preprint arXiv:0909.1085 (2009).

11. S. Vannitsem, P. Ekelmans, Earth System Dynamics 9, 1063 (2018).

12. J. A. Francis, S. J. Vavrus, Geophysical Research Letters 39, 1 (2012).

13. E. A. Barnes, Geophysical Research Letters 40, 4734 (2013).

14. D. E. Horton, C. B. Skinner, D. Singh, N. S. Diffenbaugh, Nature climate change 4, 698 (2014). 
15. J. Cattiaux, Y. Peings, D. Saint-Martin, N. Trou-Kechout, S. J. Vavrus, Geophysical Research Letters 43, 8259 (2016).

16. D. Coumou, G. Di Capua, S. Vavrus, L. Wang, S. Wang, Nature Communications 9, 1 (2018).

17. R. Vautard, et al., Environmental Research Letters 11, 114009 (2016).

18. P. Yiou, et al., Advances in Statistical Climatology, Meteorology and Oceanography 3, 17 (2017).

19. A. Jézéquel, et al., Environmental Research Letters 13, 054007 (2018).

20. D. Faranda, G. Messori, P. Yiou, Scientific reports 7, 41278 (2017).

21. D. Faranda, M. C. Alvarez-Castro, G. Messori, D. Rodrigues, P. Yiou, Nature communications 10, 1316 (2019).

22. P.-A. Michelangeli, R. Vautard, B. Legras, Journal of the atmospheric sciences 52, 1237 (1995).

23. M. Vrac, P. Vaittinada Ayar, P. Yiou, International Journal of Climatology 34, 472 (2014).

24. H. W. Rust, M. Vrac, M. Lengaigne, B. Sultan, Journal of Climate 23, 6573 (2010).

25. D. P. Van Vuuren, et al., Climatic Change 122, 373 (2014).

26. M. Vrac, et al., Natural Hazards and Earth System Sciences 12, 2769 (2012).

27. S. I. Seneviratne, et al., Changes in climate extremes and their impacts on the natural physical environment (2012).

28. A. Jézéquel, P. Yiou, S. Radanovics, Climate Dynamics (2018). 
29. B. Oueslati, P. Yiou, A. Jzquel, Scientific reports 9, 2859 (2019).

30. P. Yiou, et al., Submitted to: Bullettin of the American Meteorological Society .

31. S. Scher, G. Messori, Geophysical Research Letters 46, 2931 (2019).

32. F. E. Otto, et al., Nature Climate Change 6, 813 (2016).

33. D. Faranda, G. Messori, P. Yiou, Submitted to: Climate Dynamics (2019).

34. J. Zscheischler, et al., Nature Climate Change 8, 469 (2018).

\section{Acknowledgments}

This paper was supported by EUPHEME project, which is part of ERA4CS, an ERA-NET initiated by JPI Climate and co-funded by the European Union (Grant 690462), ERC grant no. 338965-A2C2 DF and PY were further supported by a CNRS-INSU LEFE/MANU grant (DINCLIC project).

NCEP Reanalysis data are provided by the NOAA/OAR/ESRL PSD, Boulder, Colorado, USA, from their Web site at https://www.esrl.noaa.gov/psd/

We acknowledge the World Climate Research Programme's Working Group on Coupled Modelling, which is responsible for CMIP, and we thank the climate modeling groups (listed in the Supplementary Table 1) for producing and making available their model output. For CMIP the U.S. Department of Energy's Program for Climate Model Diagnosis and Intercomparison provides coordinating support and led development of software infrastructure in partnership with the Global Organization for Earth System Science Portals 


\begin{tabular}{|l|l|l|l|l|}
\hline Event & Type & Region Affected & Starting Date & Ending Date \\
\hline CS1956-SE & Cold Spell & Southern and Central Europe & $01 / 02 / 1956$ & $20 / 02 / 1956$ \\
\hline CS2012-SE & Cold Spell & Italy \& the Balkans & $05 / 02 / 2012$ & $15 / 02 / 2012$ \\
\hline CS2013-WE & Cold Spell & Western and Central Europe & $10 / 03 / 2013$ & $16 / 03 / 2013$ \\
\hline CS2017-SE & Cold Spell & Italy \& Greece & $05 / 01 / 2017$ & $08 / 01 / 2017$ \\
\hline FL2014-BK & Flood & The Balkans & $31 / 08 / 2014$ & $06 / 09 / 2014$ \\
\hline FL2016-FR & Flood & France & $28 / 05 / 2016$ & $31 / 05 / 2016$ \\
\hline FL2018-06-FR & Flood & France & $11 / 06 / 2018$ & $12 / 06 / 2018$ \\
\hline FL2018-10-FR & Flood & France & $14 / 10 / 2018$ & $15 / 10 / 2018$ \\
\hline HW2003-EU & Heatwave & Central, Western Europe & $01 / 08 / 2003$ & $15 / 08 / 2003$ \\
\hline HW2010-RU & Heatwave & Eastern Europe \& Russia & $01 / 07 / 2010$ & $18 / 07 / 2010$ \\
\hline HW2017-SE & Heatwave & Southern Europe & $01 / 08 / 2017$ & $10 / 07 / 2017$ \\
\hline HW2018-NE & Heatwave & Northern Europe & $15 / 07 / 2018$ & $02 / 08 / 2018$ \\
\hline
\end{tabular}

Table 1: Description of the extreme events analyzed in this study. More details in the Supplementary Material.
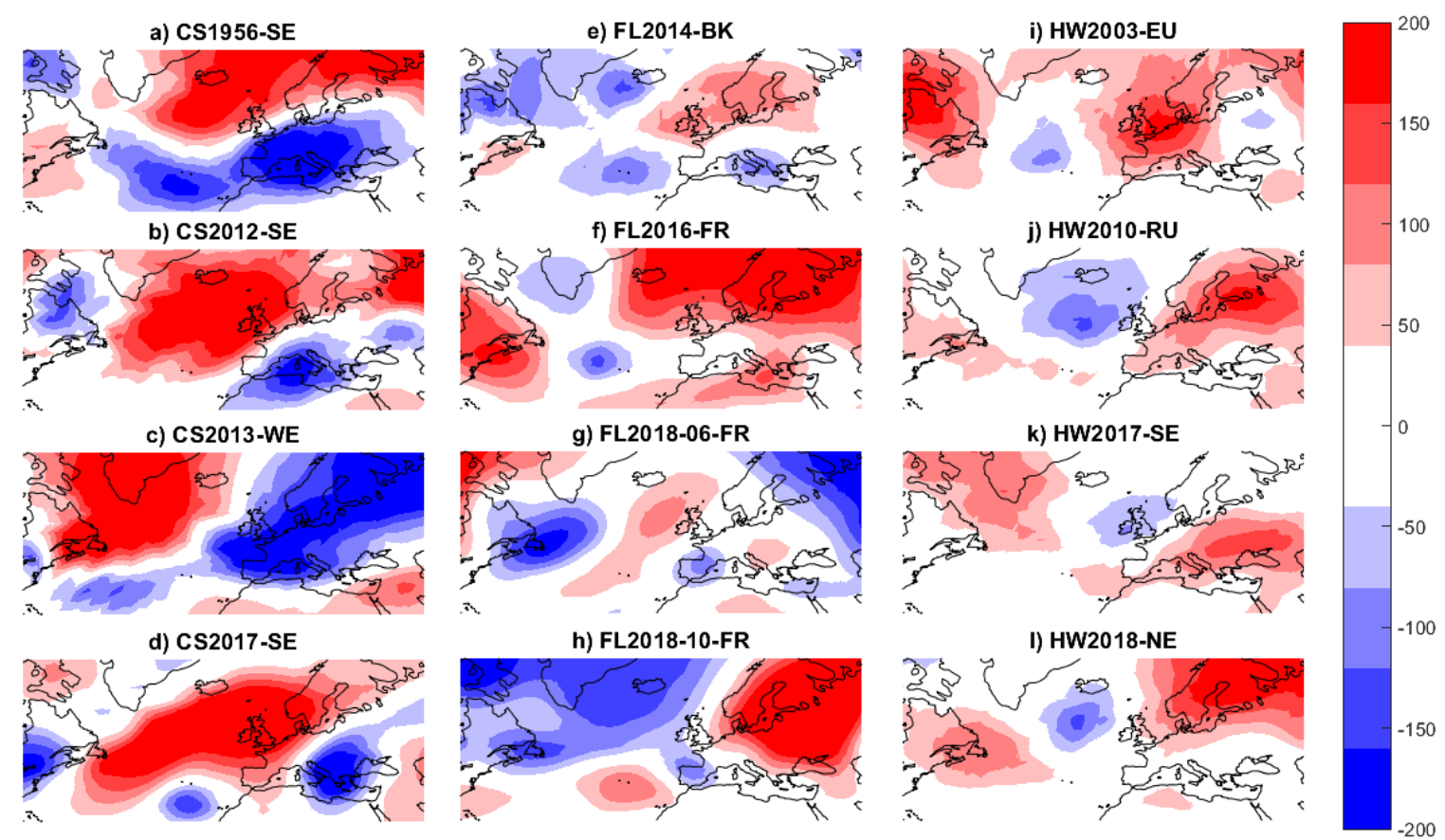

Figure 1: NCEP Geopotential height Z500 anomalies (in meters) computed subtracting the monthly climatology from the average Z500 field of the event. a-d) cold spell events, e-h) extreme precipitations, i-l) heatwaves. Details reported in Table 1. See Supplemental material for a description of the events. 

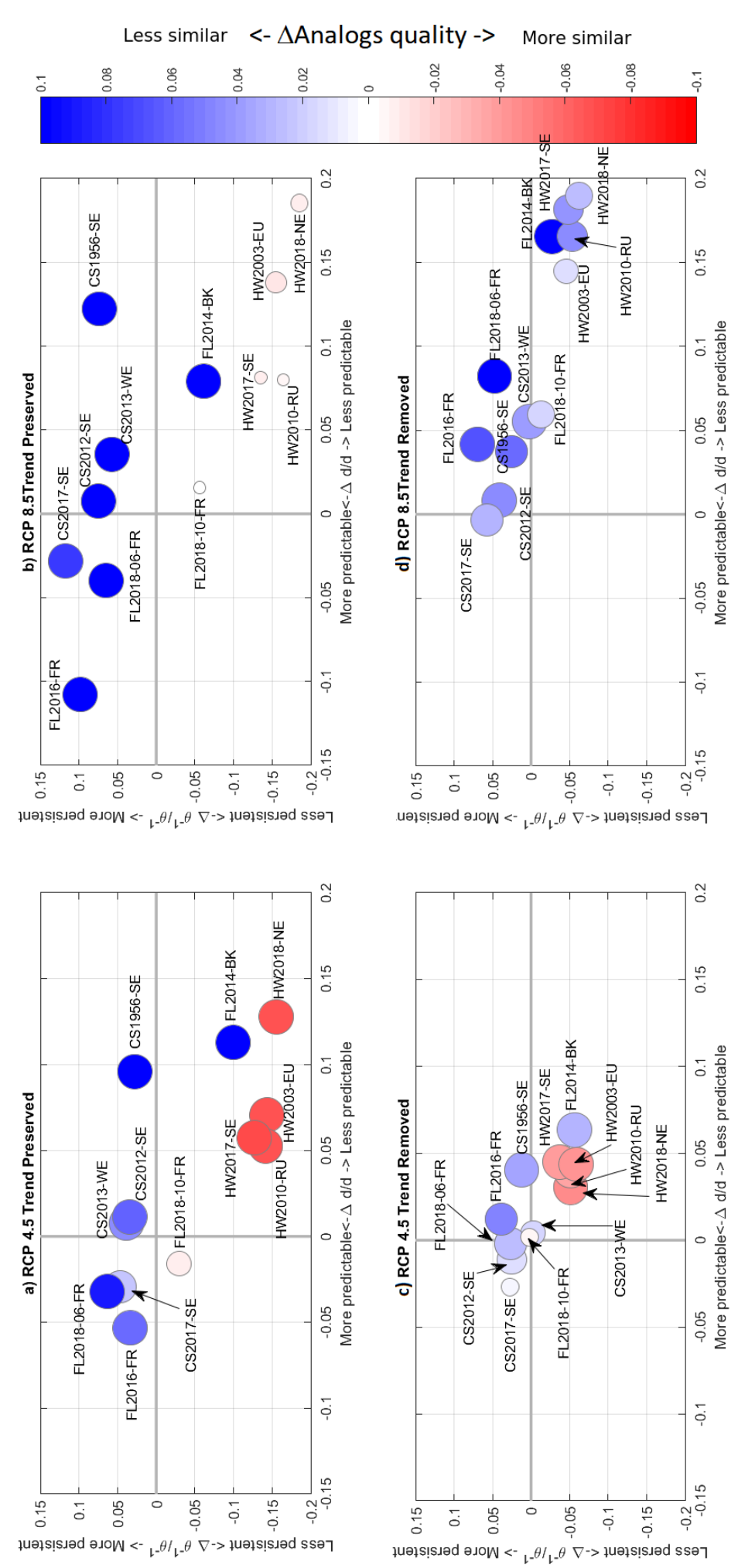

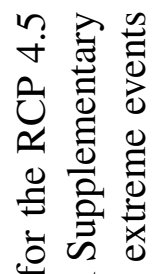

(ข) $\cong$

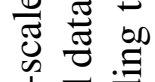

흘

过

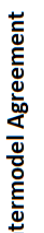

晃需

당 bo

कू ఠิ

ํํ

ส

륭

สิ

సิ

$8 \stackrel{0}{Ð}$

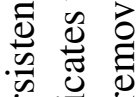

过.

次芜

齐

政

:

쥼

苋 \&

可

है

.

为

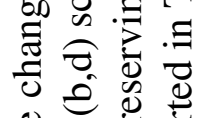

约

䒕它

Q

$\ddot{\sim} \overline{0} \dot{0}$

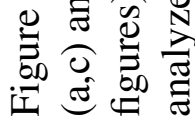




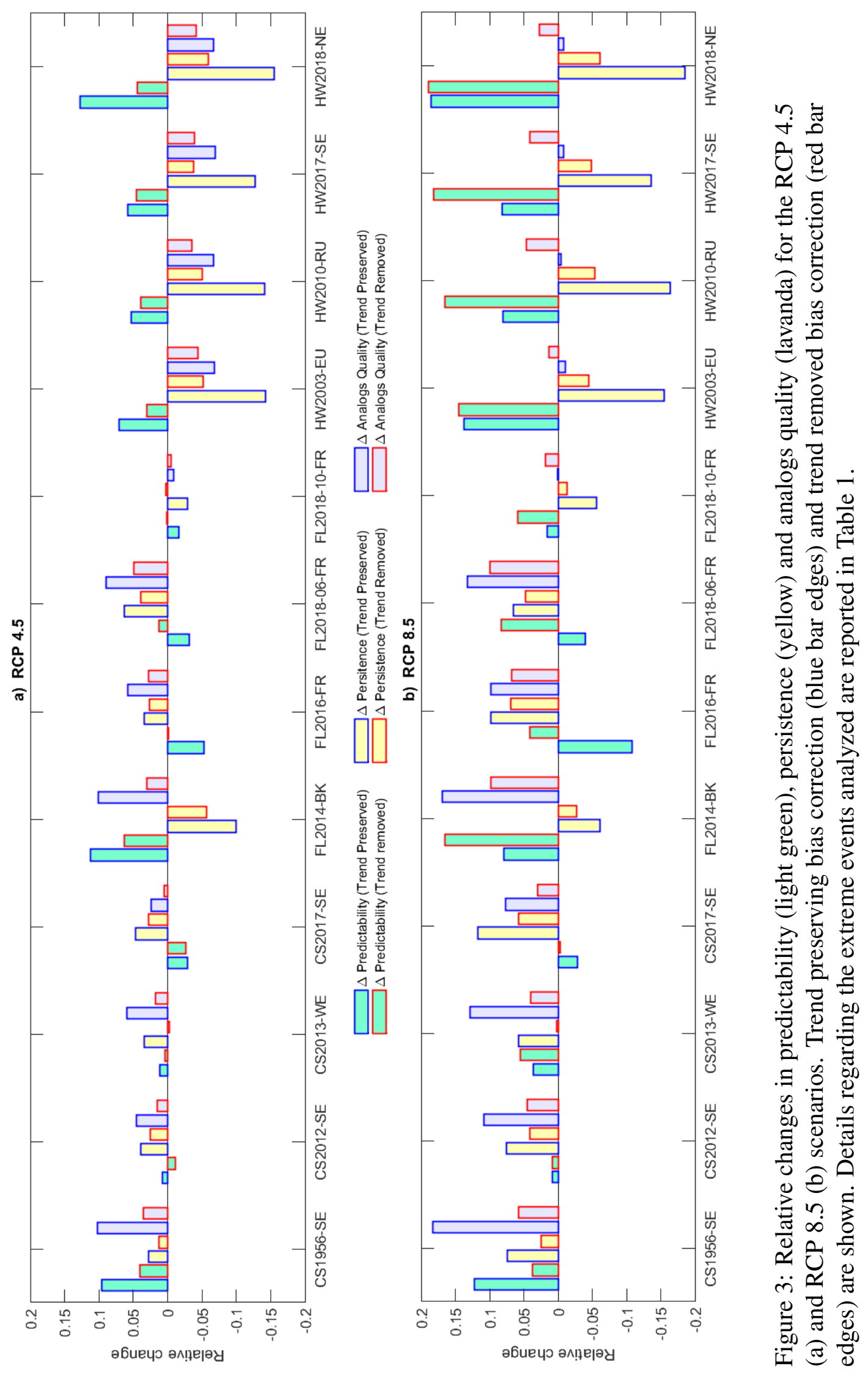


- Supplementary Material - Changes in future synoptic - circulation patterns: consequences for extreme event attribution

${ }_{4}$ Davide Faranda, ${ }^{1,2 *}$ Mathieu Vrac, ${ }^{1}$, Aglaé Jezequel $^{3}$, Soulivanh Thao ${ }^{1}$, Pascal Yiou ${ }^{1}$

${ }^{1}$ Laboratoire des Sciences du Climat et de l'Environnement LSCE-IPSL

CEA Saclay l'Orme des Merisiers, UMR 8212 CEA-CNRS-UVSQ

Université Paris-Saclay, 91191 Gif-sur-Yvette, France

${ }^{2}$ London Mathematical Laboratory, 8 Margravine Gardens, London, W68RH, UK

${ }^{3}$ ENS - Laboratoire de Mtorologie Dynamique (UMR 8539), 24 rue Lhomond, Paris,France

*To whom correspondence should be addressed; E-mail: davide.faranda@1sce.ipsl.fr

6 Materials and Methods

7 Extreme Events Analyzed

8 We provide here some characteristics of the extreme events analyzed in this study. They have

9 been selected based on their social and economical impact, as an illustration of the method.

\footnotetext{
1956 Southern Europe Cold spell (CS1956-SE). The cold spells events we analyze are all characterized by the presence of heavy snowfalls over large populated areas. The 1956 cold spell (Supplementary Figure 1) was one of the coldest and snowiest of the 20th century, especially over Italy and Serbia (1). Federico Fellini in Amarcord reproduces scenes of Rimini, a town at sea level height in Emilia Romagna region, blocked by snow walls over 1 meter high. Locations such as Marseilles, Rome, Naples and Palermo recorded important snowfall amounts.
} 
The duration of this event was very long with cold conditions persisting for about 20 days and severe effects on vegetation (2).

2012 Southern Europe Cold spell (CS2012-SE). The 2012 cold spell (Supplementary Figure 2) struck Western and Southern Europe with remarkable effects on the Adriatic sea region (3). In Bologna, over $45 \mathrm{~cm}$ of fresh snow fell in one night for a total over one meter during the whole event. Even Rome was covered by $15 \mathrm{~cm}$ of snow. The snow caused interruptions at London Heathrow airport where $10 \mathrm{~cm}$ of snow were measured. Snow fell in Mallorca for the first time since 1956. Finally the snow reached $111 \mathrm{~cm}$ height in Sarajevo and 5 people died for cold-related causes.

2013 Western Europe Cold spell (CS2013-WE). The 2013 cold spell (Supplementary Figure 3) was marked by an unusual cold and snowy weather especially in the United Kingdom and in France. The snowfall affected Scotland, Ireland but also southern England and Normandy (4). In Normandy, nuclear power plants had to reduce their operations for few days.

2017 Southern Europe Cold spell (CS2017-SE). The beginning of January 2017 (Supplementary Figure 4) was extremely cold in central, eastern and southern Europe. The Danube froze in Romania. Snowstorms affected, among other locations, Instanbul, Rome, Athens, Santorini and Majorca (5).

2014 Balkan floods (FL2014-BK). A series of storms (Supplementary Figure 5) occurred between the Adriatic regions of Italy and the Balkans (especially Croatia, Albania and Greece) at the beginning of September 2014. Extreme precipitations associated to hail, heavy rain and tornados were reported in Puglia as well as in Costal Croatia. One station in Puglia (Falcare) reported over $700 \mathrm{~mm}$ rainy in $48 \mathrm{~h}(6)$. 
2016 French floods (FL2016-FR). Continued heavy rain fell between 28 May to 31 May 2016 and caused major flooding in several departments including Seine-et Marne and Loiret $(7,8)$ (Supplementary Figure 6). $155 \mathrm{~mm}$ of rain were recorded in Melleroy, Loiret Department, which is the equivalent of 2 to 3 months of rain. The level of the Loing river at Nemours broke a 100-year record by reaching 4.63 meters. The Seine river overflowed its banks and reached a level of 6.10 meters at the Paris Austerlitz reference gauge. (9) performed an attribution study of the event and showed that anthropogenic climate change has increased the likelihood of such an event by about a factor of 2 on the Seine and Loire rivers.

June 2018 French floods (FL2018-06-FR). A serie of storms (Supplementary Figure 7) occurred in France from mid-May to mid-June 2018. In particular, between 11 and 12 June 2018 heavy rainfall struck the regions, Ile de France, Pays de Loire, Normandy, Brittany, Centre-Val de Loire and Grand Est (10). Records were broken in Ile de France and in Brittany. For instance, according to Météo-France, $75 \mathrm{~mm}$ of precipitation fell in 24 hours in Orly and $71 \mathrm{~mm}$ of precipitation fell in 24 hours in Nantes. The heavy rainfall also caused flooding, especially in the South of Paris, Brittany, Normandy and in Southwestern France.

October 2018 French floods (FL2018-10-FR). Heavy rainfall (Supplementary Figure 8) fell in the South of France on October 14-15 (11). The event was particularly extreme in Aude department. For instance, $295 \mathrm{~mm}$ of rain fell in Trèbes and the level of the Aude River in this town increased by 7 meters overnight. Heavy rainfall were also recorded at the same time in the Mediterranean islands of Corsica (France) and Sardinia (Italy).

2003 European heatwave (HW2003-EU). The 2003 European heatwave (Supplementary Figure 9) broke records of mean temperature in Western Europe in the past five centuries (12). Numerous studies have shown that climate change increased the probability of occurrence of 
such a heatwave (e.g. $(13,14))$. The maximal temperature anomaly was centered over Western in the first half of August (15), hence the choice of the dates for our study (see Table 1). The very low soil moisture exacerbated the intensity of the heatwave $(16,17)$. (13) evaluated that anthropogenic climate change increased the probability of this event at least 10 times since the preindustrial era. (18) evaluated that a trend in the atmospheric circulation that lead to that event.

2010 Russian heatwave (HW2010-RU). The 2010 Russian heatwave (Supplementary Figure $10)$ is also one of the most extreme heatwaves recorded in Europe $(19,20)$. Climate change also seemed to increase the probability of occurrence of such an event $(21,22)$. Low soil moisture and atmospheric circulation both played a role, as analyzed in (23). In (22) a threefold increase of the probability of such an event was shown. In (24) it was observed that there was no trend in the atmospheric circulation that lead to that event.

2017 Southern Europe heatwave (HW2017-SE). Western Europe and the Euro-Mediterranean region experienced long spells of heat in the Summer of 2017 (Supplementary Figure 11). Madrid (Retiro) reached 40.6C on July 13, equaling the 2012 record. Heat episodes continued into August, extending to many areas in southern Europe (25). The heatwave in early August was described as the worst heat wave since 2003 (BBC 2017) in southern Europe, with local maximum temperatures in Italy and the Balkans exceeding 40C for several days. Records were broken in southern France (e.g. 4 August, Nmes-Courbessac, 41.6C), and nighttime temperatures exceeded 30C in Corsica and Croatia. Anthropogenic climate change has increased the odds of such an event at least threefold since 1950.

Northern Europe heatwave 2018 (HW2018-NE). A heatwave struck northern Europe in the summer of 2018 (Supplementary Figure 12). Daily temperature anomalies reached 14K in 
Scandinavia, the Netherlands and Belgium, where records of temperature were broken. This heatwave was exacerbated by a drought caused by a persisting circulation anomaly. The heatwave and drought favored unprecedented forest fires in Scandinavia. This corresponds to the Scandinavian cluster type of heatwave identified by (16).

\section{Data and models used}

In this study we use geopotential height (Z500) as a proxy to describe the North Atlantic circulation. A wealth of atmospheric features, ranging from teleconnection patterns to storm track activity to atmospheric blocking can be diagnosed from the Z500 field and this field appears to be the most relevant to perform atmospheric circulation extreme event attribution. We base our study on NCEP/NCAR reanalysis data (26) over the period 1948-2018, with a horizontal resolution of $2.5^{\circ}$. The region of interest is $\left(22.5^{\circ} \mathrm{N}-70^{\circ} \mathrm{N}\right.$ and $80^{\circ} \mathrm{W}-50^{\circ} \mathrm{E}$. We analyze daily output of the Coupled Model Intercomparison Project phase 5 (CMIP5) (27) for: 16 historical simulations (Supplementary Table 1), 16 RCP4.5/8.5 projections. The historical simulations cover the period 1950-2000; the forcings are consistent with observations and include changes in: atmospheric composition due to anthropogenic and volcanic influences, solar forcing, emissions or concentrations of short-lived species and natural and anthropogenic aerosols or their precursors, as well as land use. RCP4.5 and RCP8.5 projections are projections of future climates (2051-2100) forced by two representative concentration pathway scenarios (RCPs). These result in a radiative forcing of $4.5 \mathrm{Wm}^{-2}$ and $8.5 \mathrm{Wm}^{-2}$ respectively in year 2100 , relative to pre-industrial conditions.

\section{Bias Correction procedures}

The statistical bias correction method applied is the Cumulative Distribution Function - transform (CDF-t) method, developed in (28). This approach links the cumulative distribution func- 
tion (CDF) of a climate variable (here Z500) from GCM simulations to be corrected, to the CDF of this variable from a reference dataset, here the NCEP/NCAR reanalysis dataset (29). A mathematical transformation $T$ is performed on the simulations CDF to define a new CDF as close as possible to the reference CDF. Let $F_{G h}$ and $F_{R h}$ denote respectively the CDFs of the variable of interest from the GCM and from the reference over a historical time period (here 1950-2005). We assume that, whatever the value $x$ of the variable to be corrected, the transformation $T$ allows to go from $F_{G h}$ to $F_{R h}$ :

$$
T\left(F_{G h}(x)\right)=F_{R h}(x) .
$$

Therefore, by noting that $x$ can be written as $F_{G h}^{-1}(p)$, with $p$ a probability value in $[0,1]$, the transformation $T$ can be expressed as

$$
T(p)=F_{R h}\left(F_{G h}^{-1}(p)\right) .
$$

Then, Eq. (2) is assumed to stay valid under evolving climate conditions. This means that if the GCM CDF $F_{G h}$ for the historical period becomes $F_{G f}$ in a future time period, it is assumed that $T$ enables us to estimate $F_{R f}$, the target reference CDF for the future time period, through $F_{R f}(x)=T\left(F_{G f}(x)\right)$, which is thus formulated as

$$
F_{R f}(x)=F_{R h}\left(F_{G h}^{-1}\left(F_{G f}(x)\right)\right) .
$$

Then, this future corrected CDF $F_{R f}$ allows us to perform a quantile-mapping approach (30-32) between $F_{G f}$ and $F_{R f}$ to generate values out of $F_{R f}$, respecting the GCM rank chronology. Hence, CDF-t can be considered as a variant of the empirical quantile-mapping method but within the appropriate target (here future) time period and therefore accounts for changes of $\mathrm{CDF}$ from the calibration period to the projection one.

This bias correction method is applied in two different ways. First, CDF-t is applied on a monthly basis to the raw NCEP/NCAR reanalyses and CMIP5 GCM simulations. The results 
are the non-detrended bias corrections. Secondly, CDF-t is applied, still on a monthly basis, to NCEP/NCAR reanalyses and GCM simulations from which a spatial and seasonal trend is removed. To do so, for each day, the Z500 spatial average is calculated. Next, for each calendar day (e.g., each January, 1) over the period of interest (1951-2000 or 2051-2100), a linear fit of the daily Z500 spatial average as a function of time is estimated. This spatial trend is then removed from each Z500 grid-cell value for the specific calendar day, and the spatial average value estimated by the model for the year 2006 for the calendar day is added. This ensures that a seasonality (that estimated for 2006) is preserved, with no trend in the resulting Z500 data. Those seasonally and spatially detrended data are the inputs of CDF-t, therefore providing adjusted values hereafter and in the main text referred to as detrended bias corrections.

In the present study, all bias corrections have been made through the CDF-t R package (freely available on www.r-project.org/). More theoretical and technical details, as well as first validations and comparisons can be found in (33). Various applications of CDF-t can be found in (34-37), among others.

\section{Dynamical systems metrics}

The attractor of a dynamical system is a geometric object defined in the space hosting all the possible states of the system (phase-space). Each point $\zeta$ on the attractor can be characterized by two dynamical indicators: the local dimension $d$, which indicates the number of degrees of freedom active locally around $\zeta$, and the persistence $\theta^{-1}$, a measure of the mean residence time of the system around $\zeta(38)$. To determine $d$, we exploit recent results from the application of extreme value theory to Poincaré recurrences in dynamical systems. This approach considers long trajectories of a system — in our case successions of daily SLP latitude-longitude maps — corresponding to a sequence of states on the attractor. For a given point $\zeta$ in phase space (e.g., a given SLP map), we compute the probability that the system returns within a ball of radius $\epsilon$ 
centered on the point $\zeta$. The Freitas et al. (39) theorem, modified by Lucarini et al. (40), states that logarithmic returns:

$$
g(x(t))=-\log (\operatorname{dist}(x(t), \zeta))
$$

yield a probability distribution such that:

$$
\operatorname{Pr}(z>s(q)) \simeq \exp \left[-\vartheta(\zeta)\left(\frac{z-\mu(\zeta)}{\sigma(\zeta)}\right)\right]
$$

where $z=g(x(t))$ and $s$ is a high threshold associated to a quantile $q$ of the series $g(x(t))$. Requiring that the orbit falls within a ball of radius $\epsilon$ around the point $\zeta$ is equivalent to asking that the series $g(x(t))$ is over the threshold $s$; therefore, the ball radius $\epsilon$ is simply $e^{-s(q)}$. The resulting distribution is the exponential member of the Generalized Pareto Distribution family. The parameters $\mu$ and $\sigma$, namely the location and the scale parameter of the distribution, depend on the point $\zeta$ in phase space. $\mu(\zeta)$ corresponds to the threshold $s(q)$ while the local dimension $d(\zeta)$ can be obtained via the relation $\sigma=1 / d(\zeta)$.

When $x(t)$ contains all the variables of the system, the estimation of $d$ based on extreme value theory has a number of advantages over traditional methods (e.g. the box counting algorithm $(41,42))$. First, it does not require to estimate the volume of different sets in scale-space: the selection of $s(q)$ based on the quantile provides a selection of different scales $s$ which depends on the recurrence rate around the point $\zeta$. Moreover, it does not require the a priori selection of the maximum embedding dimension as the observable $g$ is always a univariate time-series.

The persistence of the state $\zeta$ is measured via the extremal index $0<\vartheta(\zeta)<1$, an adimensional parameter, from which we extract $\theta(\zeta)=\vartheta(\zeta) / \Delta t . \theta(\zeta)$ is therefore the inverse of the average residence time of trajectories around $\zeta$ and it has unit of a frequency (in this study $1 /$ days). If $\zeta$ is a fixed point of the attractor $\theta(\zeta)=0$. For a trajectory that leaves the neighbor- 
Supplementary Table 1: List of CMIP5 Models Analysed. The resolution refers to the average horizontal resolution.

\begin{tabular}{|l|l|l|l|l|}
\hline No. & Model & Institution/ID & Country & Reolution \\
01 & BCC-CSM1-M & Beijing Climate Center & China & $1.125 \times 1.125$ \\
03 & BCC-CSM1-1 & Beijing Climate Center & China & $2.81 \times 2.79$ \\
04 & CANU-ESM & Beijing Normal University Earth System Model & China & $2.81 \times 2.81$ \\
05 & CMCC-CMS & Canadian Centre for Climate Modelling and Analysis & Canada & $2.81 \times 2.81$ \\
06 & CNRM-CM5 & Centro Euro-Mediterraneo sui Cambiamenti Climatici & Italy & $1.87 \times 1.87$ \\
07 & GFDL-ESM2G & Geophysical Fluid Dynamics Laboratory, NOAA & France & $1.40 \times 1.40$ \\
08 & GFDL-ESM2M & Geophysical Fluid Dynamics Laboratory, NOAA & USA & $2.5 \times 2.02$ \\
09 & HadGEM2-CC & MetOffice-Hadley Centre & UK & $1.87 \times 1.25$ \\
10 & IPSL-CM5A-MR & Institute Pierre Simon Laplace, IPSL & France & $2.5 \times 1.26$ \\
11 & IPSL-CM5B-LR & Institute Pierre Simon Laplace, IPSL & France & $3.75 \times 1.89$ \\
12 & MIROC-ESM-CHEM & MIROC & Japan & $2.81 \times 2.79$ \\
13 & MPI-ESM-LR & Max Planck Institute for Meteorology, MPI & Germany & $1.87 \times 1.87$ \\
14 & MPI-ESM-MR & Max Planck Institute for Meteorology, MPI & Germany & $1.87 \times 1.87$ \\
15 & MRI-CGCM3 & Meteorological Research Institute, MRI & Japan & $1.125 \times 1$. \\
16 & NorESM1-M & Norwegian Climate Center & Norway & $2.5 \times 1.89$ \\
\hline
\end{tabular}

hood of $\zeta$ at the next time iteration, $\theta=1$. To estimate $\theta$, we adopt the Süveges estimator (43).

For further details on the the extremal index, see (44).

\section{References}

1. M. Unkašević, I. Tošić, Theoretical and applied climatology 120, 29 (2015).

2. A. Menzel, H. Seifert, N. Estrella, International journal of biometeorology 55, 921 (2011).

3. I. Janeković, H. Mihanović, I. Vilibić, M. Tudor, Journal of Geophysical Research: Oceans 119, 3200 (2014).

4. D. LeComte, Weatherwise 67, 20 (2014).

5. J. A. Luque-Espinar, R. M. Mateos, I. García-Moreno, E. Pardo-Igúzquiza, G. Herrera, Natural Hazards 89, 985 (2017). 
6. P. Groenemeijer, et al., Bulletin of the American Meteorological Society 98, 2641 (2017).

7. R. Davies, France - Thousands Evacuated After River Levels Hit 100 Year High FloodList (2016).

8. R. Davies, France Floods - 1 More Dead, Levels of the Seine Rise in Paris FloodList (2016).

9. S. Philip, et al., Journal of Hydrometeorology 19, 1881 (2018).

10. R. Davies, France - Record Rain Causes Floods and Landslides in Paris and North FloodList (2018).

11. R. Davies, France - Deadly Floods in South West After 244mm of Rain in 6 Hours FloodList (2018).

12. A. Menzel, Meteorologische Zeitschrift 14, 75 (2005).

13. P. A. Stott, D. A. Stone, M. R. Allen, Nature 432, 610 (2004).

14. M. Beniston, Geophys. Res. Lett. 31 (2004).

15. J. Cattiaux, A. Ribes, Bull. Amer. Meteorol. Soc. (2018).

16. M. Stéfanon, P. Drobinski, F. D’Andrea, N. De Noblet-Ducoudré, Journal of Geophysical Research Atmospheres 117, 1 (2012).

17. E. M. Fischer, S. I. Seneviratne, P. L. Vidale, D. Lüthi, C. Schär, Journal of Climate 20, 5081 (2007).

18. A. Jézéquel, et al., Environmental Research Letters 13, 054007 (2018). 
19. D. Barriopedro, E. M. Fischer, J. Luterbacher, R. M. Trigo, R. Garcia-Herrera, Science 332, $220(2011)$.

20. S. Russo, J. Sillmann, E. M. Fischer, Environmental Research Letters 10 (2015). 124003.

21. S. Rahmstorf, D. Coumou, Proceedings of the National Academy of Sciences of the United States of America 108, 17905 (2011).

22. F. E. L. Otto, N. Massey, G. J. van Oldenborgh, R. G. Jones, M. R. Allen, Geophys. Res. Lett. 39 (2012). L04702.

23. M. Hauser, R. Orth, S. I. Seneviratne, Geophys. Res. Lett. 43, 2819 (2016).

24. A. Jézéquel, et al., Climatic Change (2018).

25. S. F. Kew, et al., Bull. Amer. Meteorol. Soc. 100, S49 (2019).

26. E. Kalnay, et al., Bulletin of the American Meteorological Society 77, 437 (1996).

27. K. E. Taylor, R. J. Stouffer, G. A. Meehl, Bulletin of the American Meteorological Society 93, 485 (2012).

28. P. Michelangeli, M. Vrac, H. Loukos, Geophys. Res. Lett. 36, L11708 (2009).

29. E. Kalnay, et al., Bulletin of the American Meteorological Society 77 (3), 437 (1996).

30. H. Panofsky, G. Brier, Some applications of statistics to meteorology, Tech. rep., University Park, Penn. State Univ. (1958).

31. Z. Haddad, D. Rosenfeld, Q. J. R. Meteorol. Soc. 123, 1283 (1997).

32. M. Déqué, Global Planet. Change 57, 16 (2007).

33. M. Vrac, et al., Natural Hazards and Earth System Sciences 12, 2769 (2012). 
34. P. Oettli, B. Sultan, C. Baron, M. Vrac, Environ. Res. Lett. 6 (2011).

35. M. Troin, et al., Climate Dynamics 46 (2015).

36. R. G. C. S. V. M. A. M. S. B. S. D. D. C. G. F. A.-S. J. Defrance, D., J.-P. Vanderlinden, Proceedings of the National Academy of Sciences of the United States of America (PNAS) 114, 6533 (2017).

37. J. S. O. A. V. M. D. D. S. B. N. T. Adjoua, M.F., Earth System Dynamics 9, 313 (2018).

38. D. Faranda, G. Messori, P. Yiou, Scientific reports 7, 41278 (2017).

39. A. C. M. Freitas, J. M. Freitas, M. Todd, Probability Theory and Related Fields 147, 675 (2010).

40. V. Lucarini, D. Faranda, J. Wouters, Journal of statistical physics 147, 63 (2012).

41. L. S. Liebovitch, T. Toth, physics Letters A 141, 386 (1989).

42. N. Sarkar, B. B. Chaudhuri, IEEE Transactions on systems, man, and cybernetics 24, 115 (1994).

43. M. Süveges, Extremes 10, 41 (2007).

44. V. Lucarini, et al., Extremes and recurrence in dynamical systems (John Wiley \& Sons, 2016). 

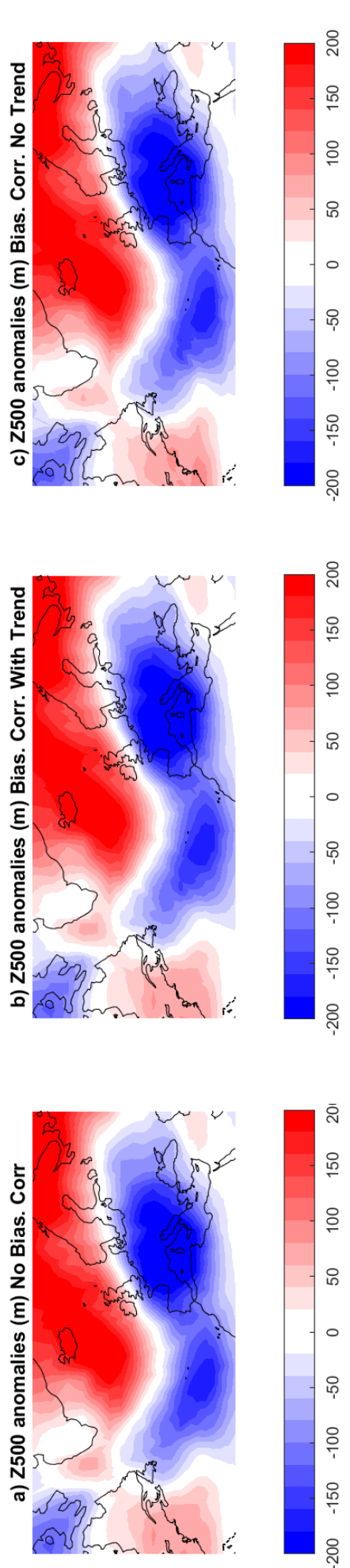
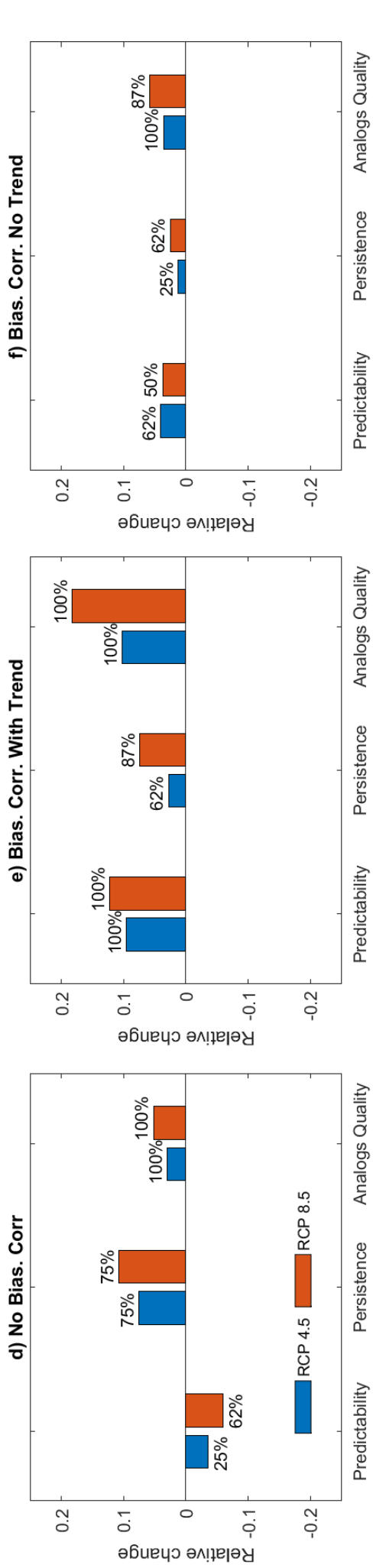

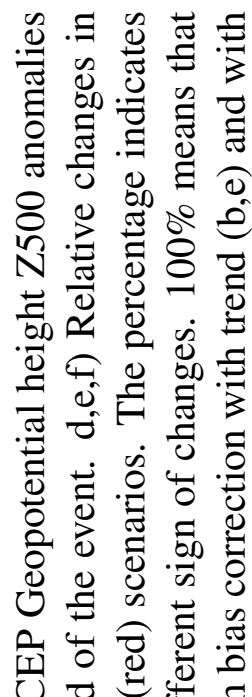

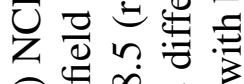

00 \& 8 i

สิ

웜

ปั่

ชั

U I n

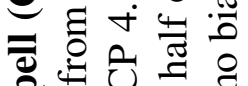

क 00 范

응 豞

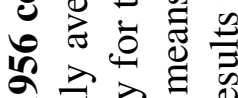

을 골

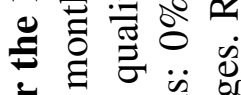

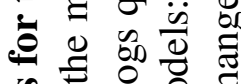

.20

尝吉䒕

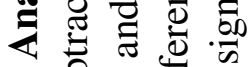

$\because$ 完 $巳 巳$

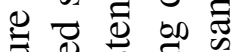

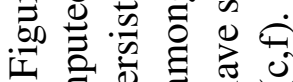

I

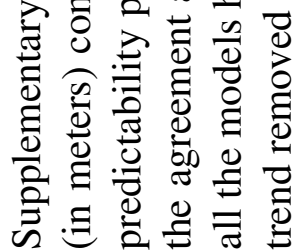



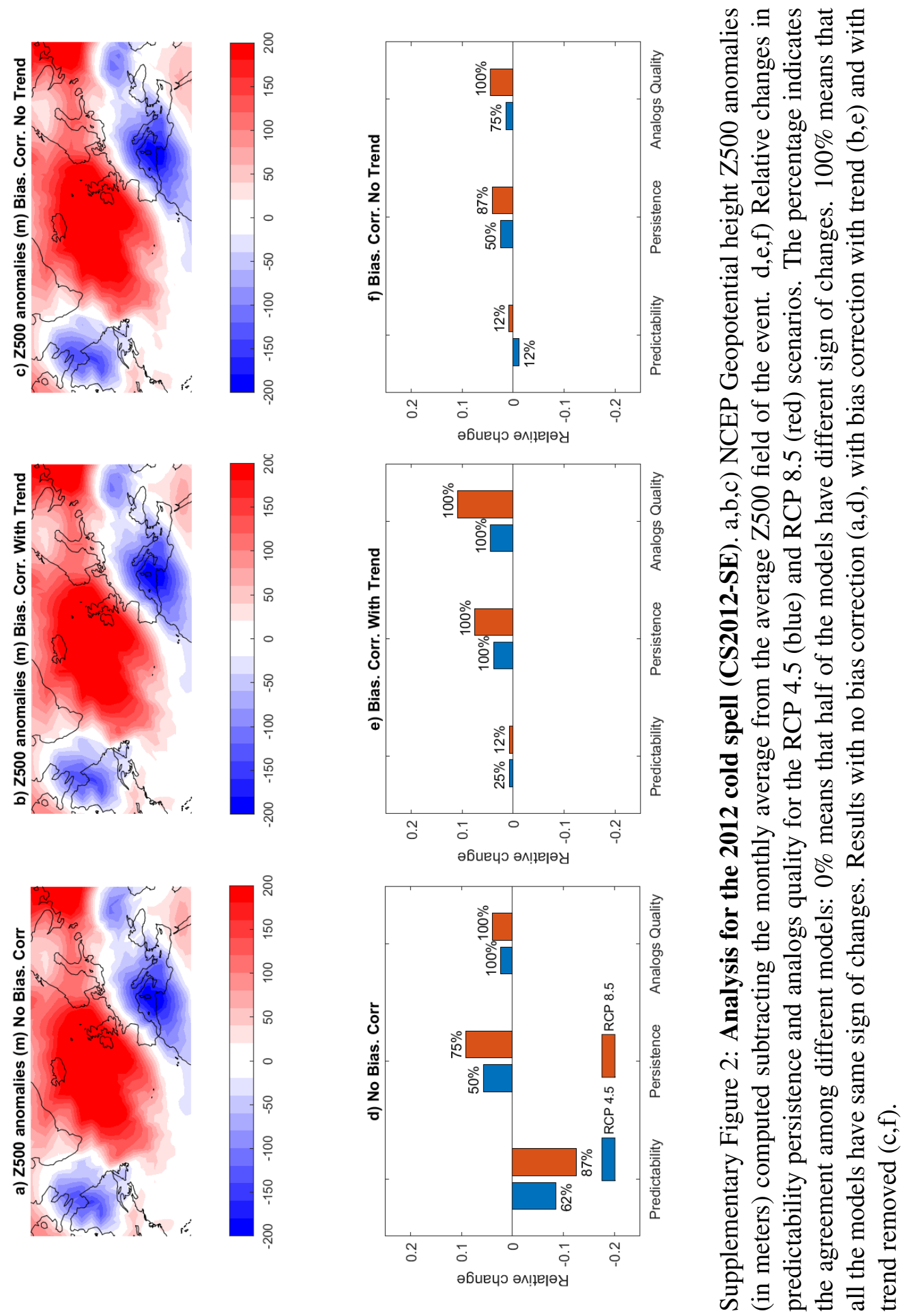

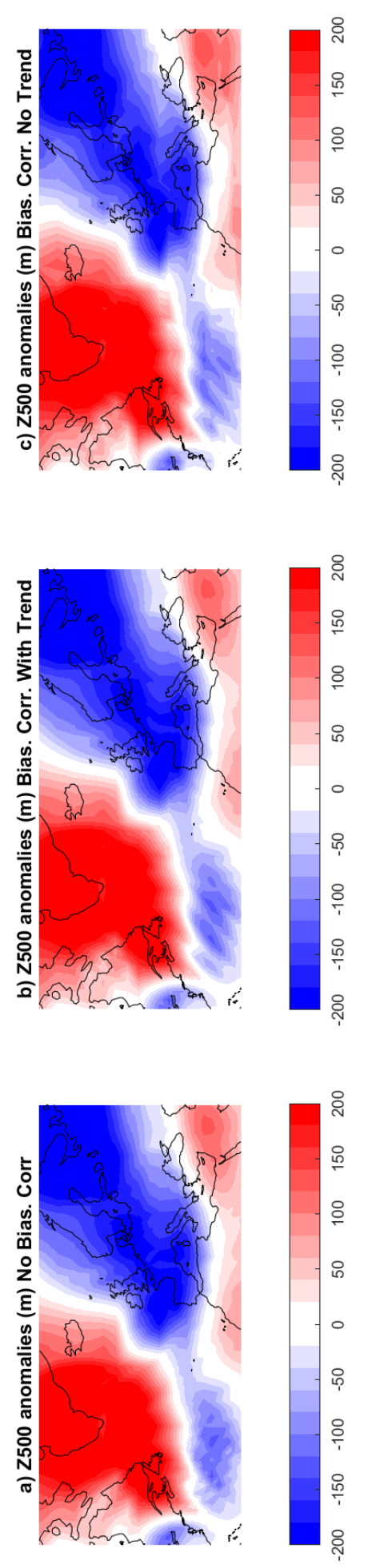
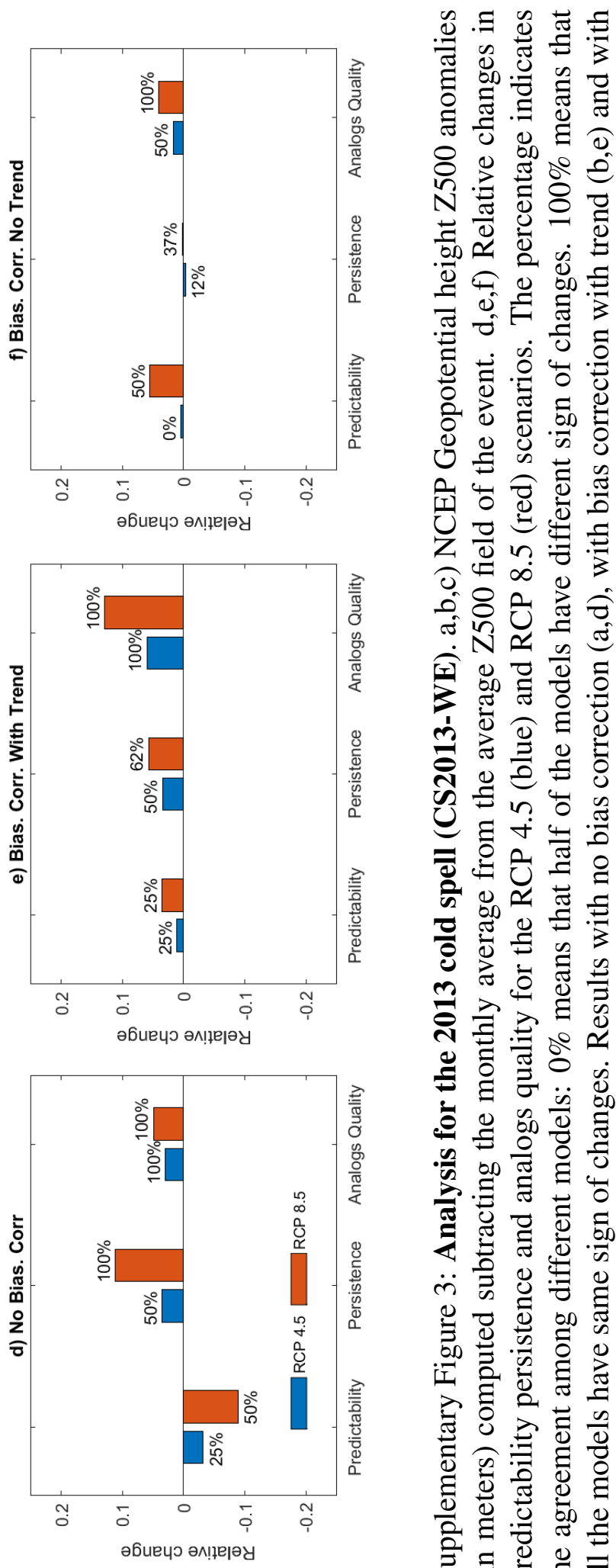

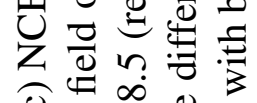
ชิ 000 สิ

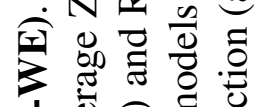
ต่ สิ บิ =

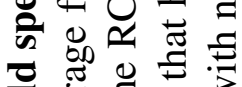

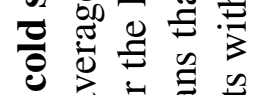
光 के

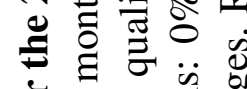

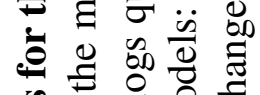
ฝ.

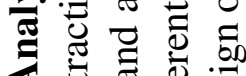

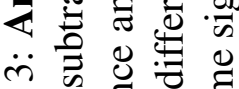

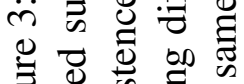

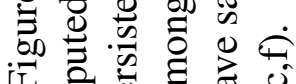

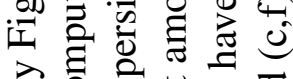

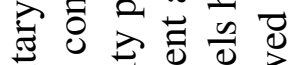

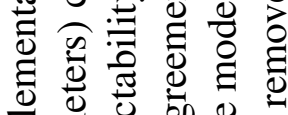

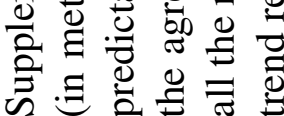



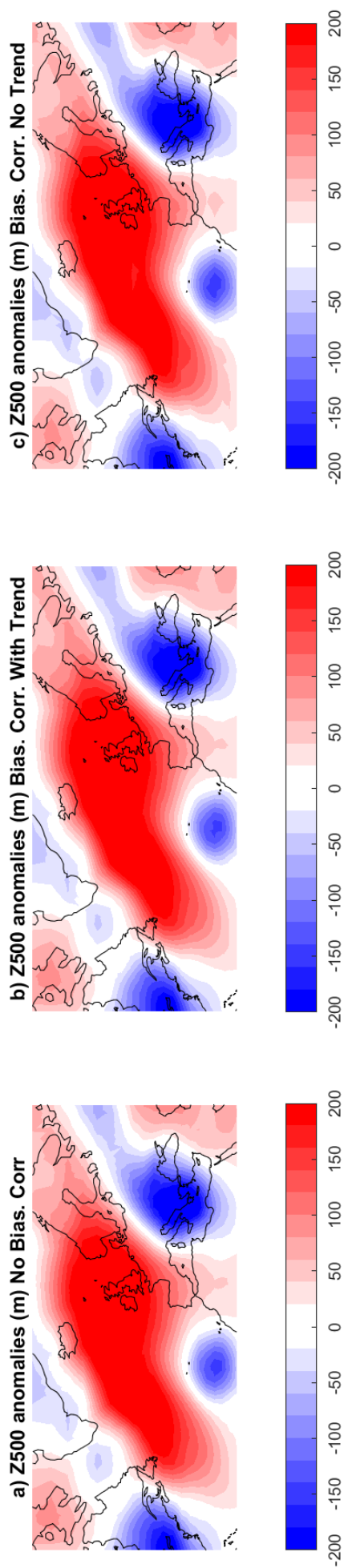
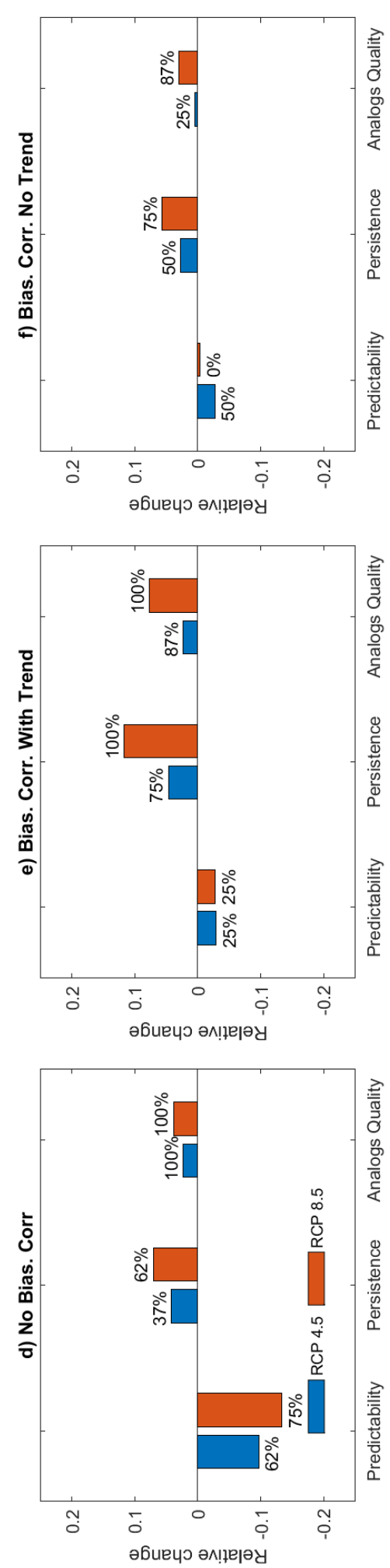

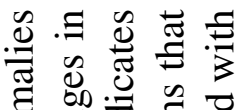
‡ี $\begin{array}{llll}1 & 0 & 0 & 0 \\ 8 & 0 & 0 & 0 \\ 8 & 0 & 0\end{array}$

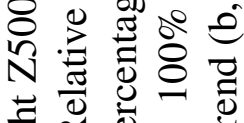

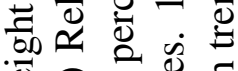
ब纯

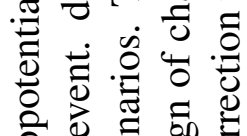
总

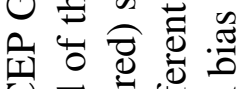

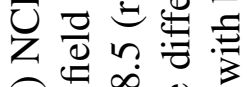
0ิ 800 क $N$ 的

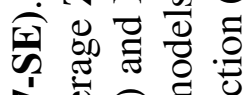
त ब సิ

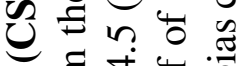

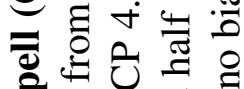
क 등 矛

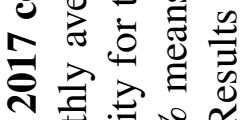
总泀泀 光 - 5 क 之. $\Xi \cong ّ$

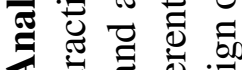
य $\ddot{\nabla}$ के 멍 可

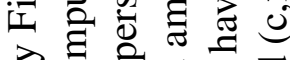

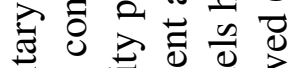

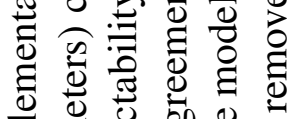

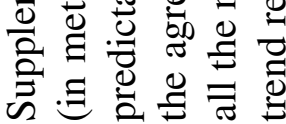



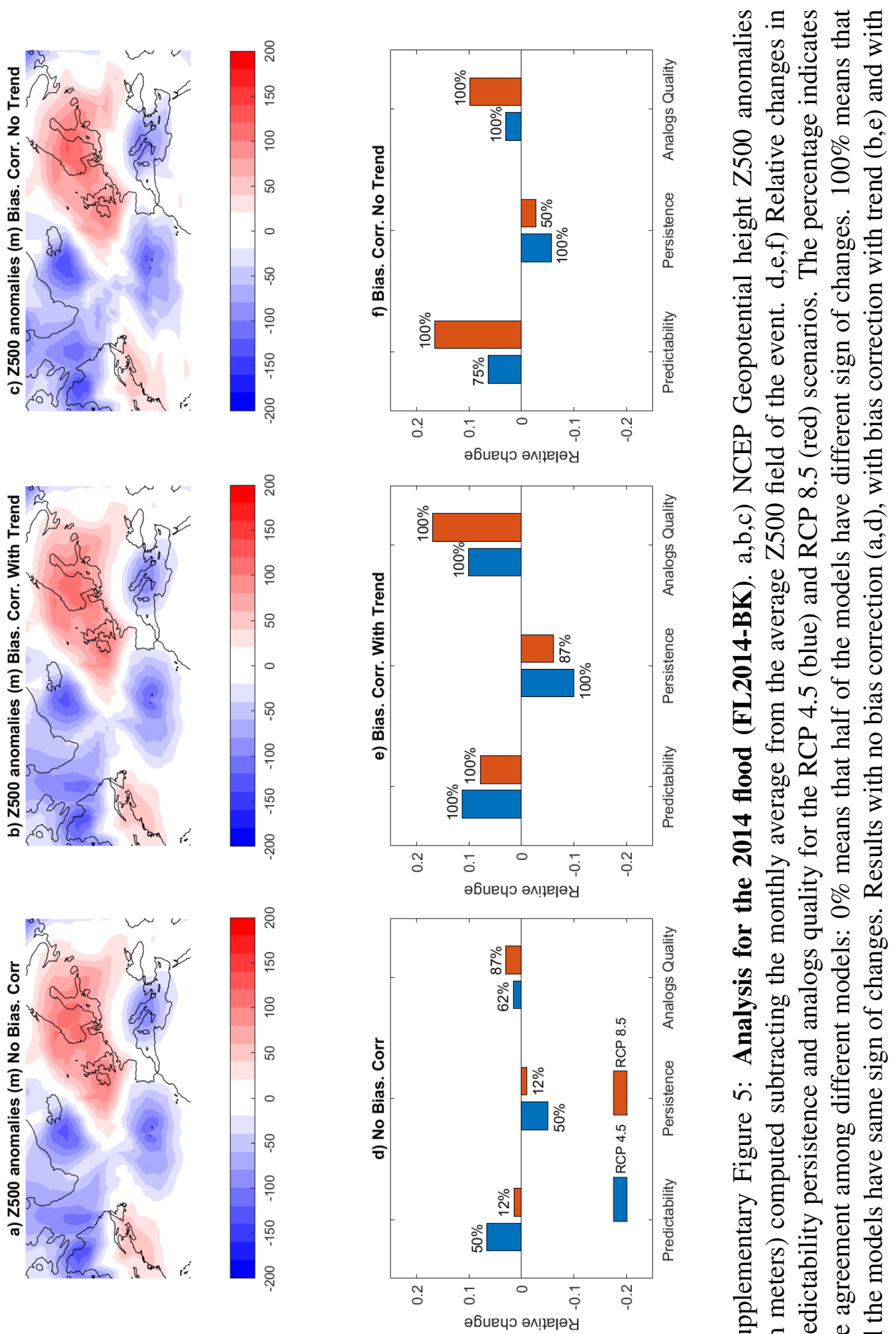

을

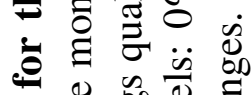

용요

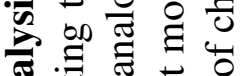

¿

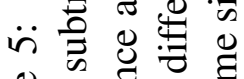

글 에

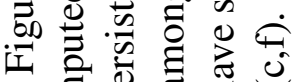

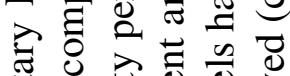

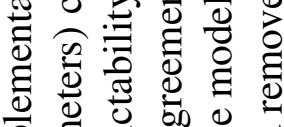

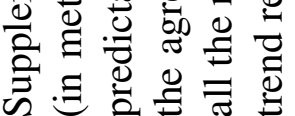



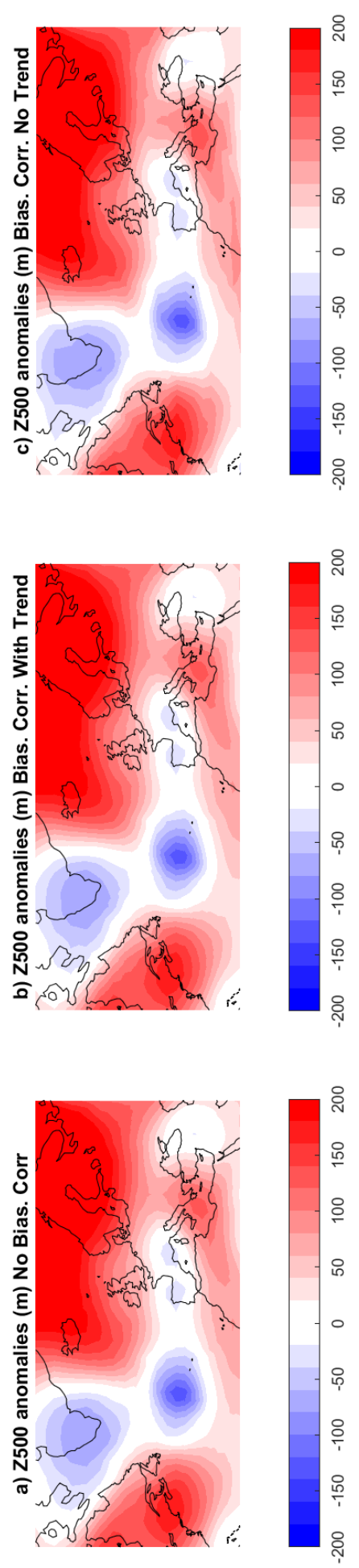
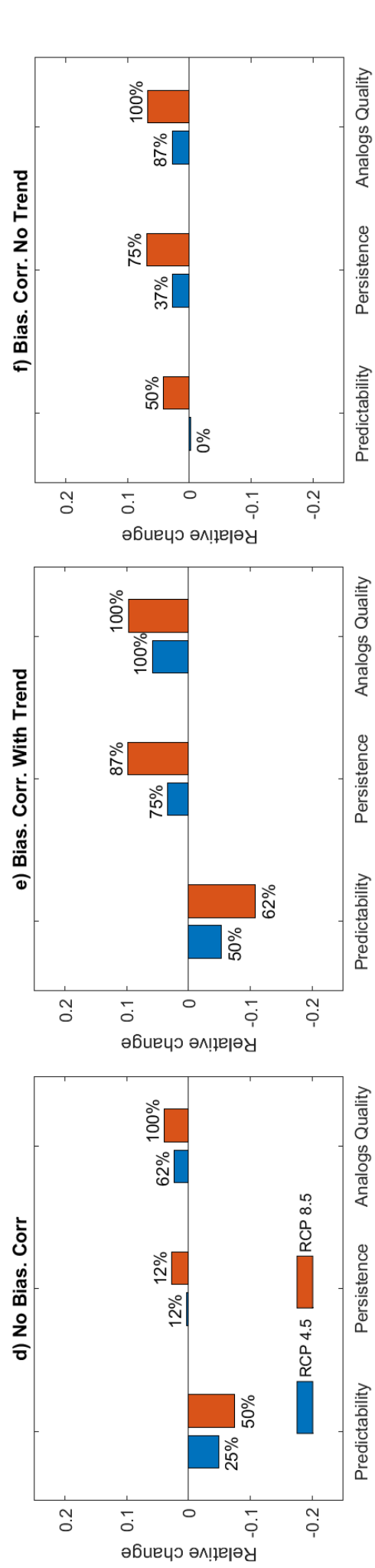

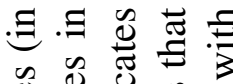
总 ป ส 8 壱 $N \simeq \stackrel{\Delta}{\Delta} \doteq$

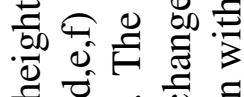

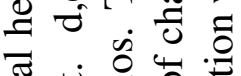

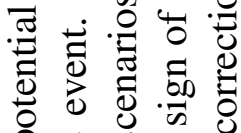
足

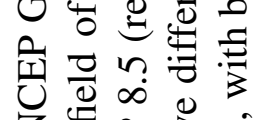
乙过 0 8 过

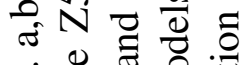
ชิ

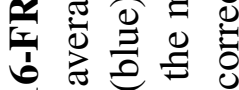
ํํำ

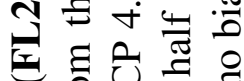

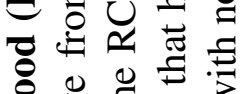

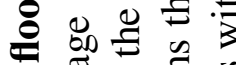
它苛

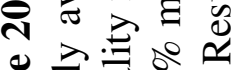
을 츨

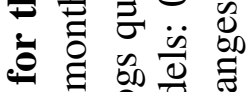

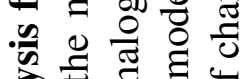

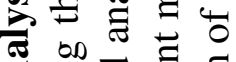

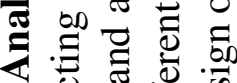

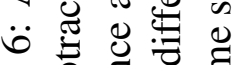
范泀

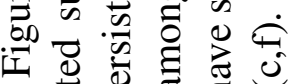

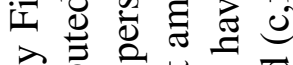

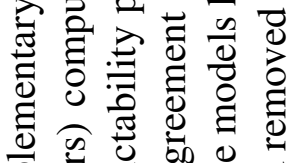

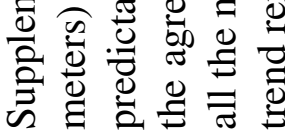



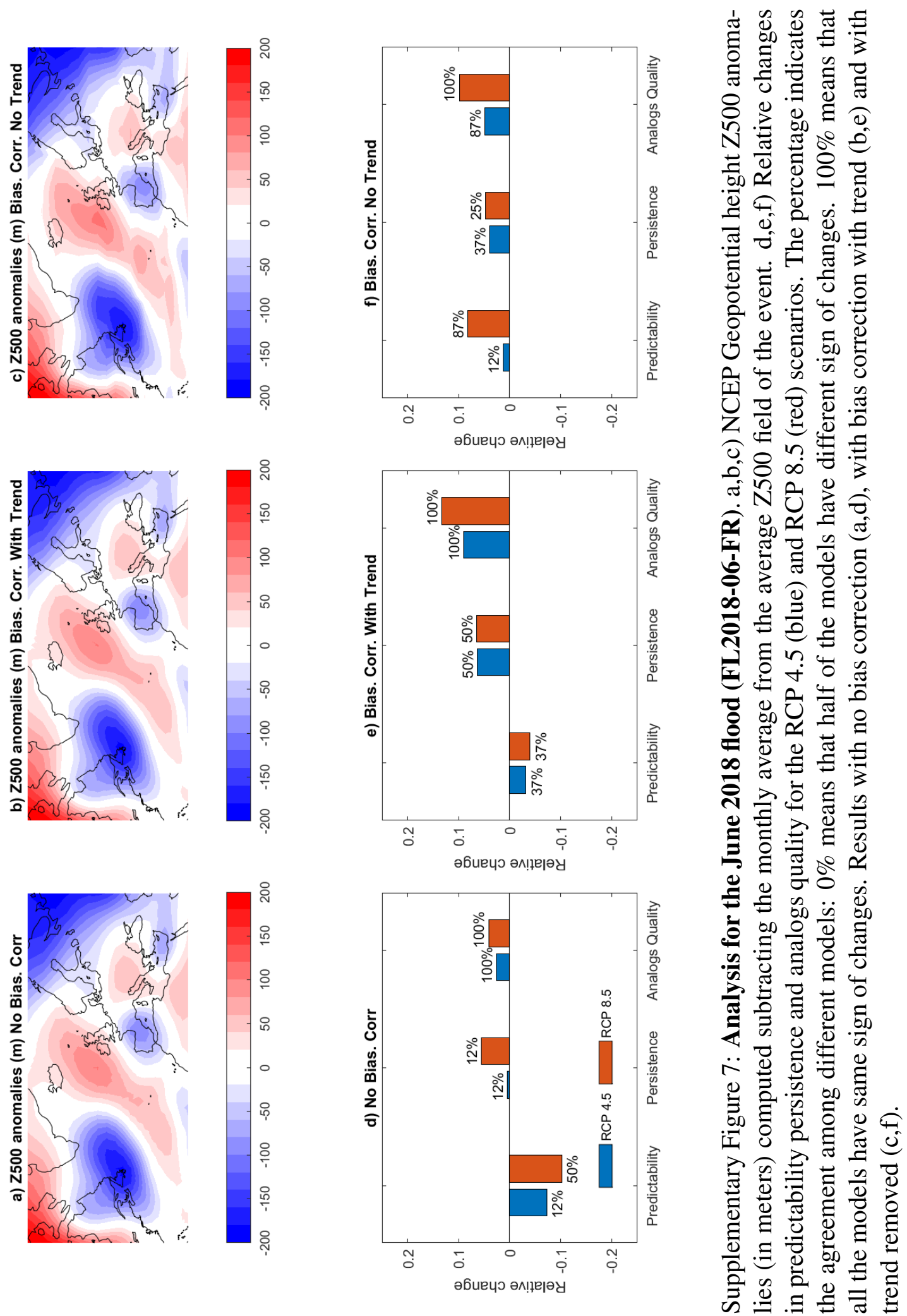

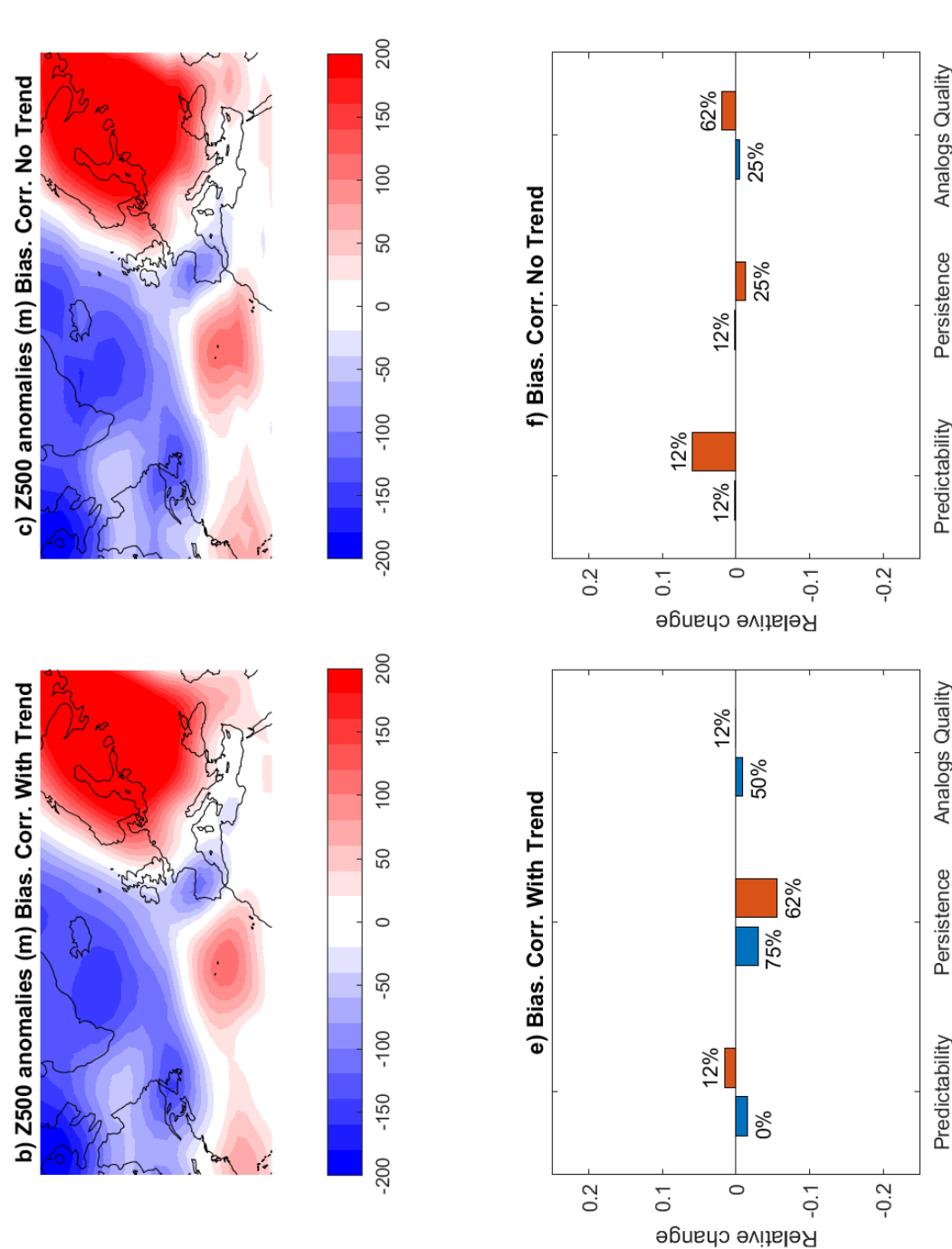

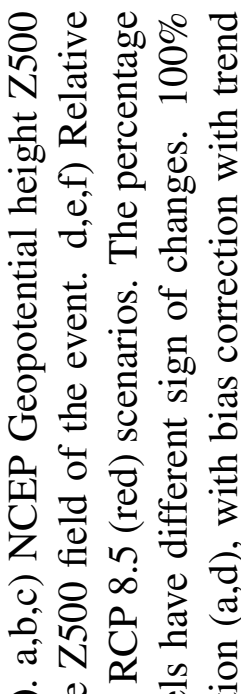

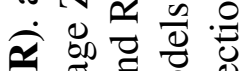
造

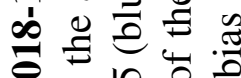
กี ฉ

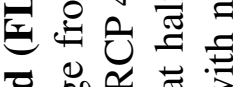

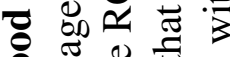

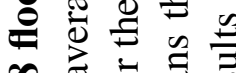

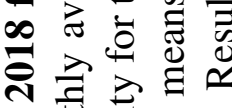

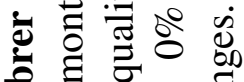
을 0 D
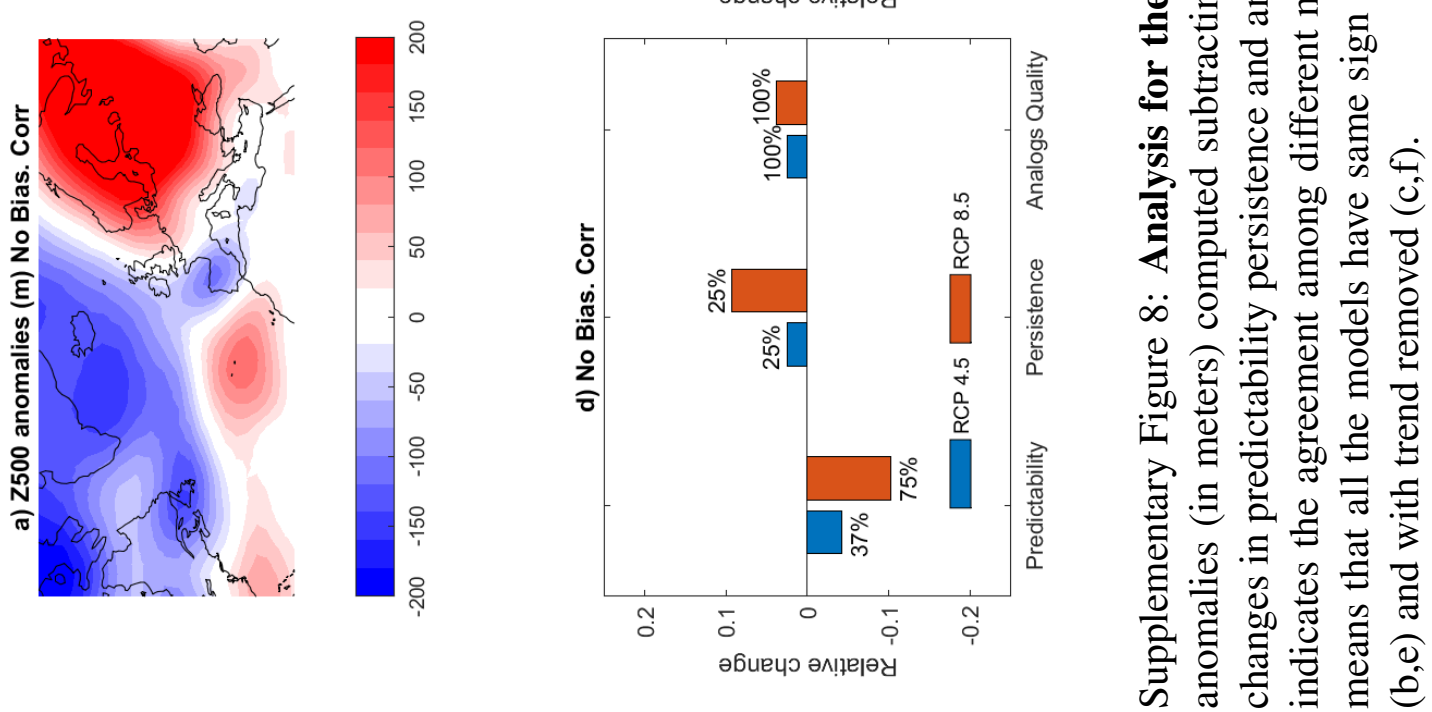

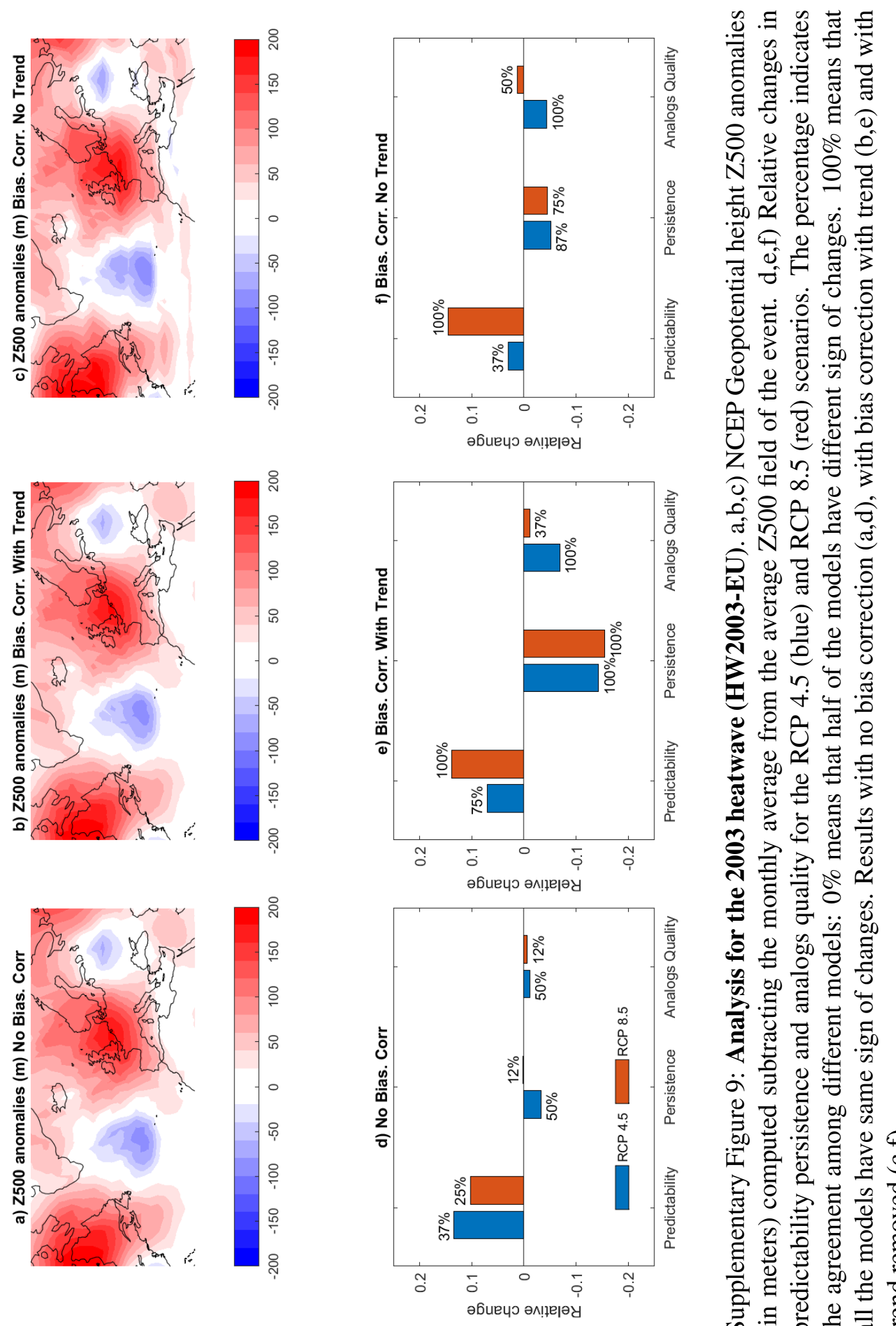

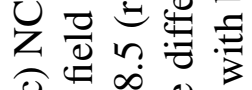

ชิ

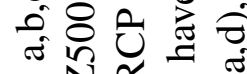

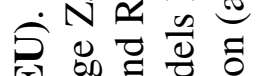

ต่

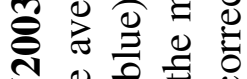

No

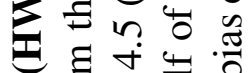

$\stackrel{0}{0}$

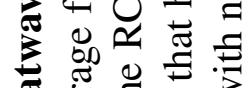

ฮั

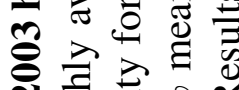

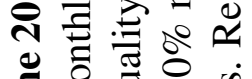

¿

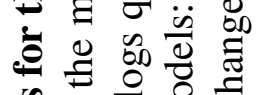

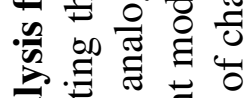

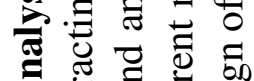

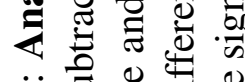

aे

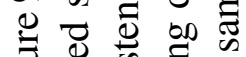

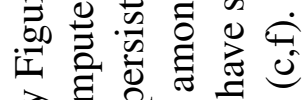

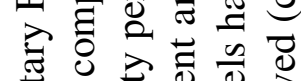

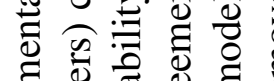

ฮี ญ ত্ড

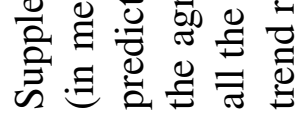



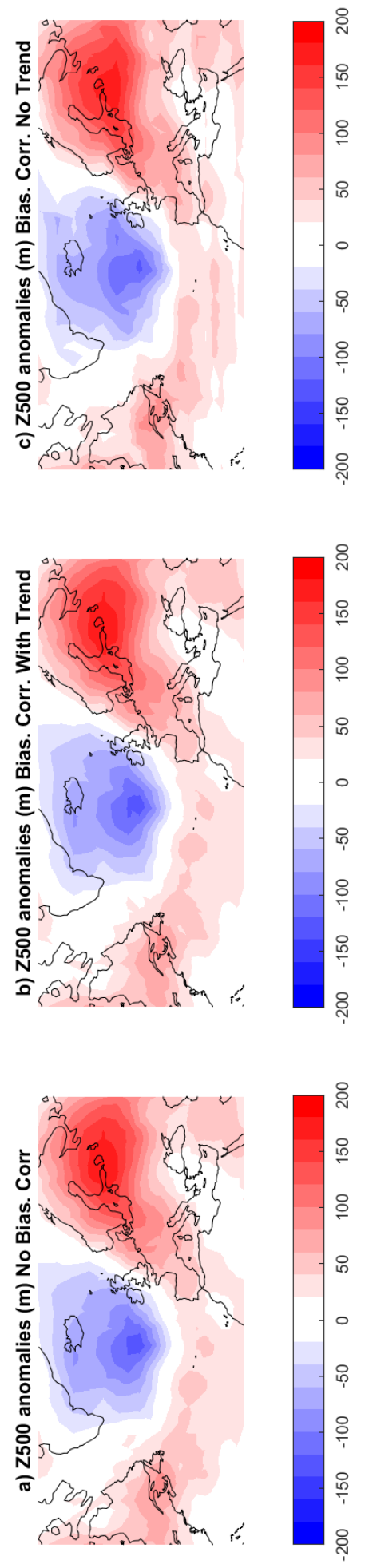
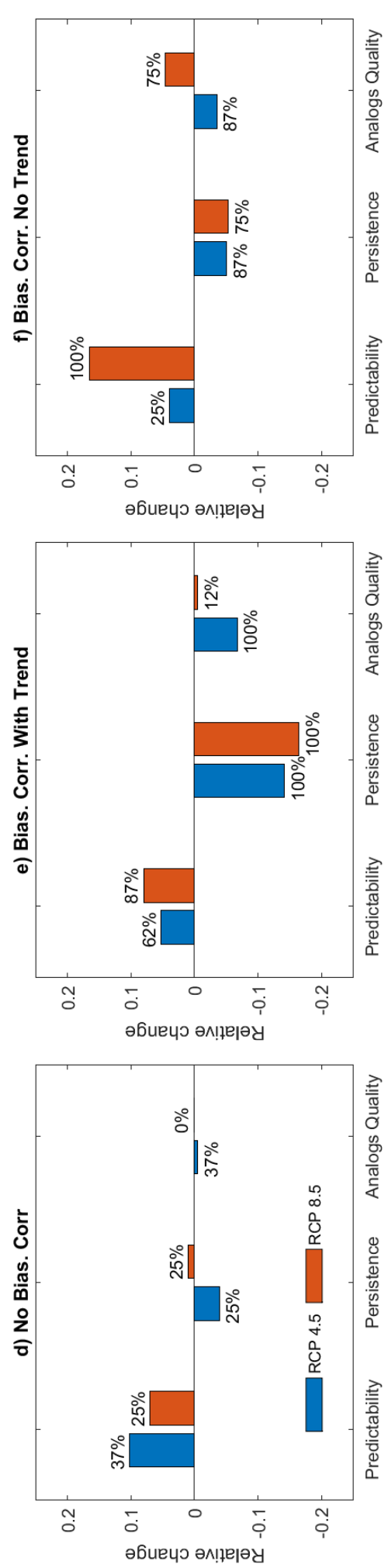

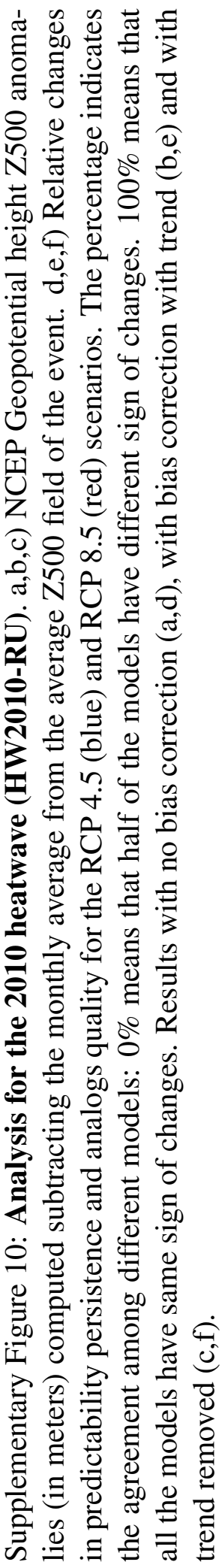



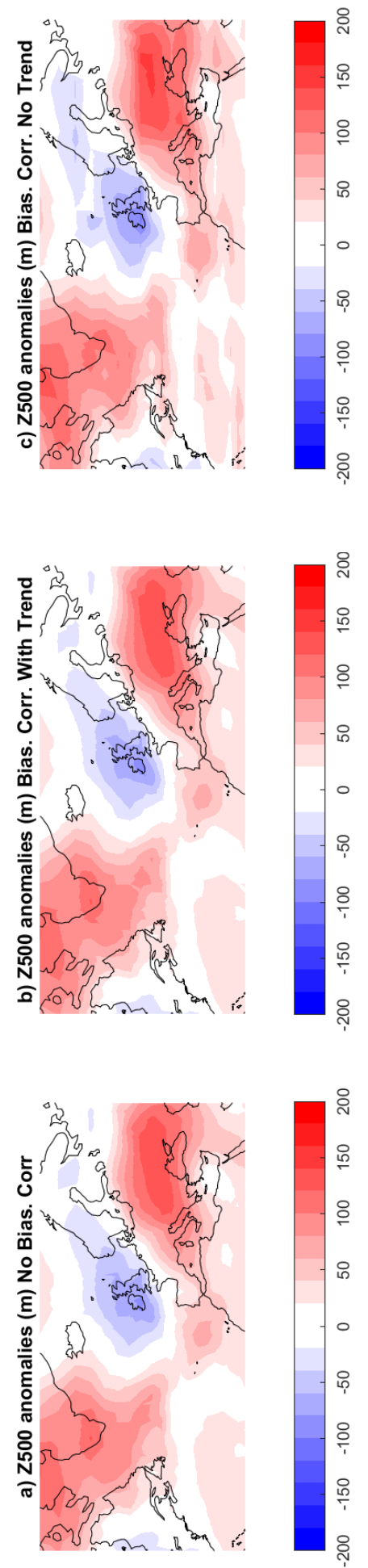
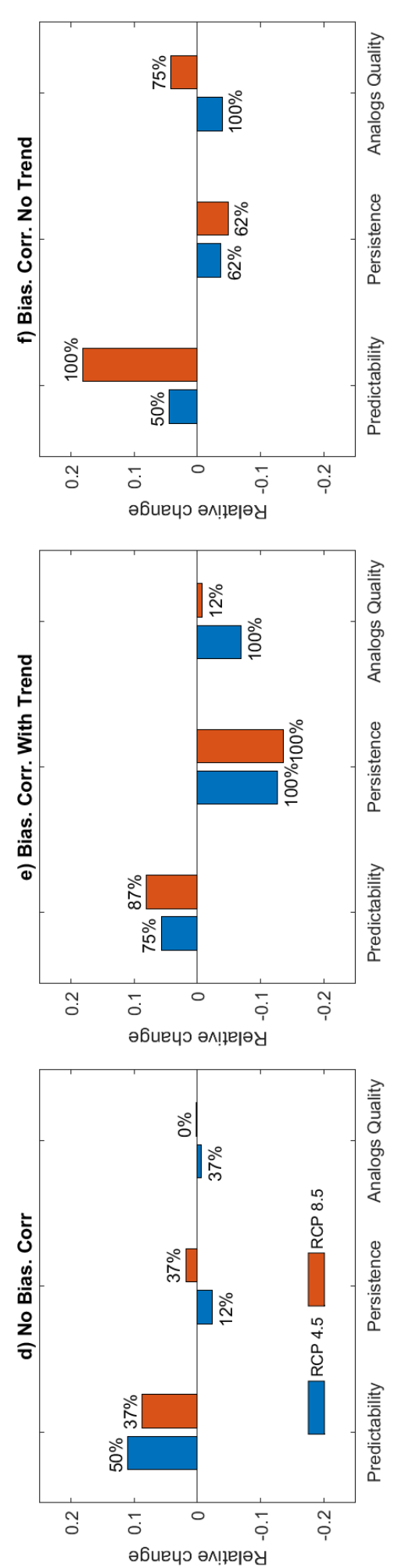

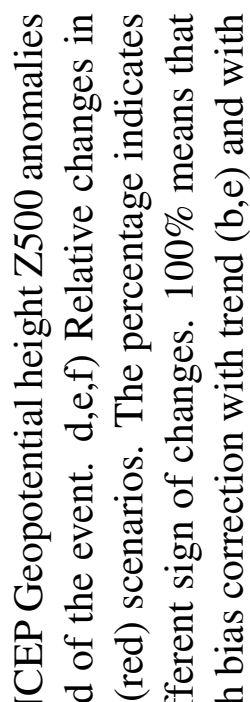

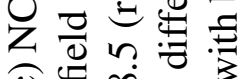
o $\infty$ i กิ 80 ठิ กำ 됭 Ð 듕

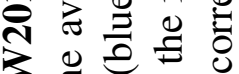
\&

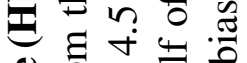

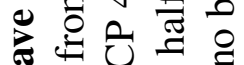
造 可

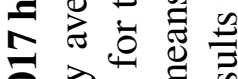
국츨 ช 元志 $\ddot{b} \Xi \begin{array}{ll}0 \\ 0\end{array}$ 요용 .

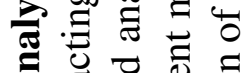

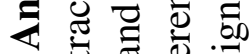

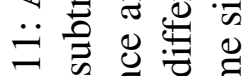

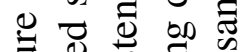

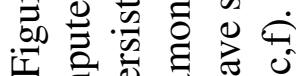

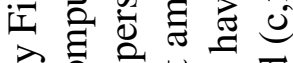

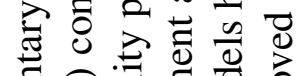
离

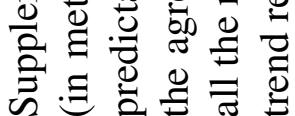



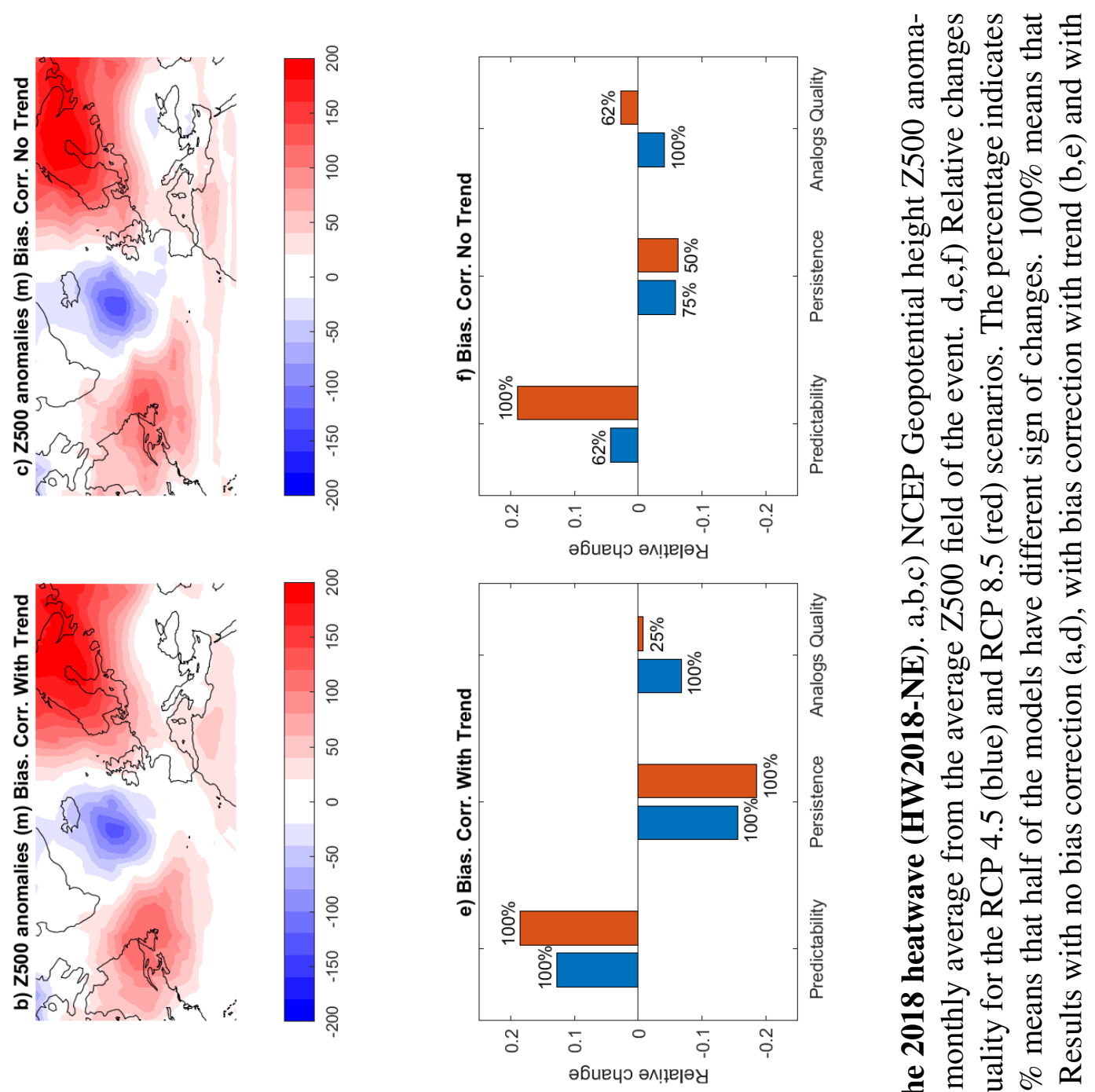

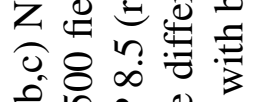

สิ

(ิ)

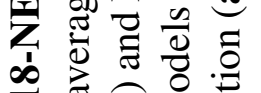

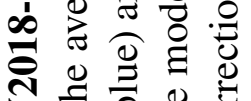

ก气

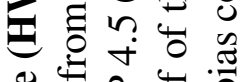

¿

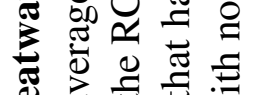

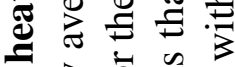

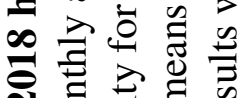

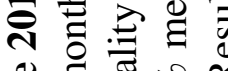
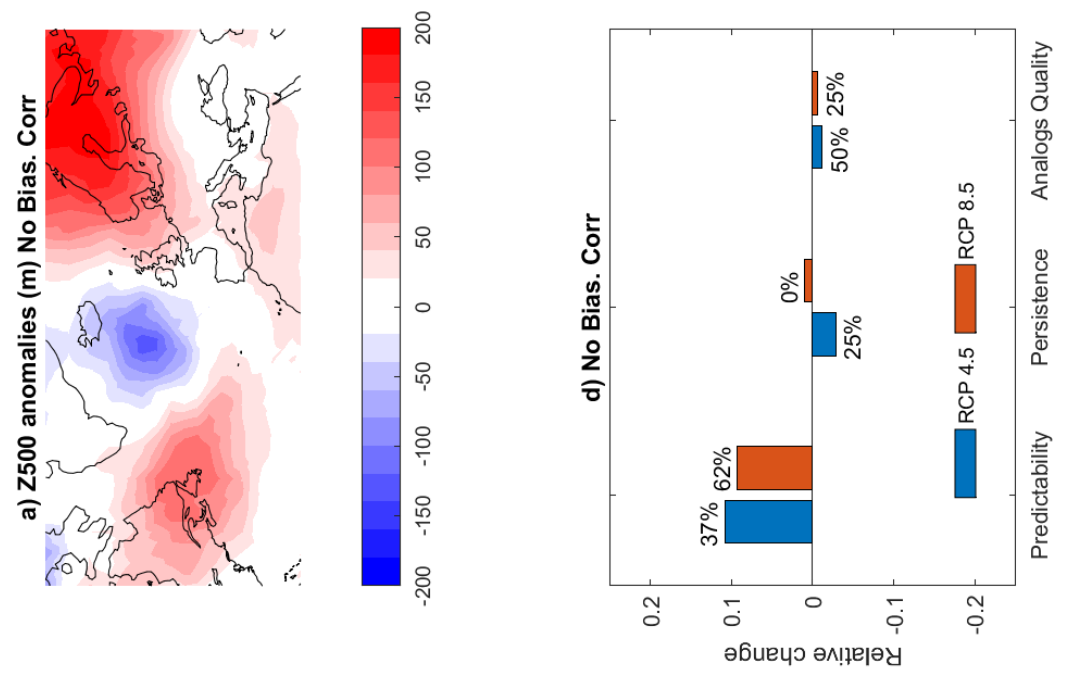

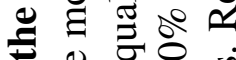

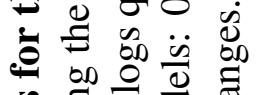

里 㐘

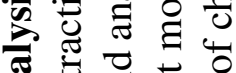

可 氙

य

ปั

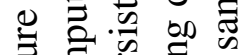

क्ञ

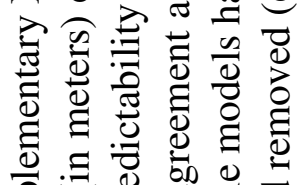

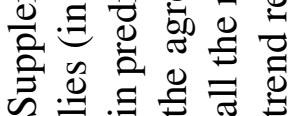

